

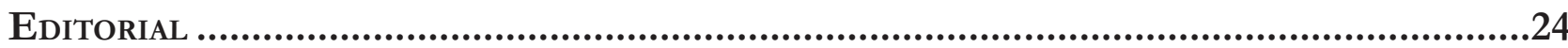

O Direito na fronteira da razão: Psicologia, neurociência e economia comportamental................... 24 Patrícia Perrone Campos Mello e Sergio Nojiri

I. NeURodireito: COGNIÇão, EMOÇÃo, JUÍZOS MORAIS E CIÊNCIA ..........................................26

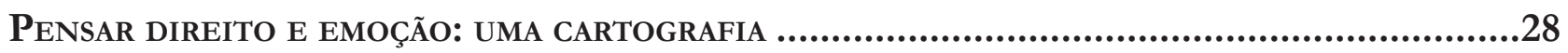

Nevita Maria Pessoa de Aquino Franca Luna

Neurodireito: o início, o fim E O MEIO

Carlos Marden e Leonardo Martins Wykrota

ENSAIO JURÍDICO SOBRE A RACIONALIDADE HUMANA: MAIORES, CAPAZES E IRRACIONAIS

André Perin Schmidt Neto e Eugênio Facchini Neto

DIVERGÊNCIAS DE PRINCÍPIO: ARGUMENTOS JURÍDICOS E MORAIS EM UM CENÁRIO DE DESACORDOS SOCIAIS

André Matos de Almeida Oliveira, Pâmela de Rezende Côrtes e Leonardo Martins Wykrota

CONSILIÊNCIA E A POSSIBILIDADE DO NEURODIREITO: DA DESCONFIANÇA À RECONCILIAÇÃO DISCIPLINAR.....

Thaís de Bessa Gontijo de Oliveira e Renato César Cardoso

MODELOS DE MORALIDADE

Molly J. Crockett

A INFELIZ BUSCA POR FELICIDADE No DiREITo

Úrsula Simões da Costa Cunha Vasconcellost, Noel Struchiner e Ivar Hannikainen

Além da liberdade: PersPeCtivas Em Nietzsche.

Lucas Costa de Oliveira

A mediaÇão de CONFlitos SOb a PERSPECTIVA do DESENVOLVIMENTO HUMANO: AS CONTRIBUIÇÕES DA PSICOLOGIA POSITIVA

Simone de Biazzi Ávila Batista da Silveira e Deise Brião Ferraz

Neuroimagiologia e aValiação de ResPonsabilidade

Nicole A. Vincent 
ANÁLISE CRÍTICA DA ORIENTAÇÃO DE CIDADÃOS COMO MÉTODO PARA OTIMIZAR DECISÕES PÚBLICAS POR MEIO DA TÉCNICA NUDGE.

Luciana Cristina Souza, Karen Tobias França Ramos e Sônia Carolina Romão Viana Perdigão

Políticas públicas e o deVer de monitoramento: “LEVANdo os Direitos A SÉrio". .252 Ana Paula de Barcellos

Nudges E POLÍticas PÚblicas: uM MECANISMO DE COMBATE AO TRABALHO EM CONDIÇÃo ANÁLOGA À DE ESCRAVO .267

Amanda Carolina Souza Silva, Débhora Renata Nunes Rodrigues e Saul Duarte Tibaldi

REDUZINDO A TRIBUTAÇÃO COGNITIVA: LIÇÕES COMPORTAMENTAIS PARA A DIMINUIÇÃO DOS EFEITOS PSICOLÓGICOS ADVERSOS DA POBREZA.............................................................288 Leandro Novais e Silva, Luiz Felipe Drummond Teixeira, Gabriel Salgueiro Soares e Otávio Augusto Andrade Santos

Políticas PÚBLICAS EM SUICÍDIO: DO PATERNALISMO CLÁSSICO AO PATERNALISMO LIBERTÁRIO E NUDGING

Davi de Paiva Costa Tangerino, Gabriel Cabral e Henrique Olive

Nudges COMO POLÍticA PÚbliCA PARA AUMENTAR O ESCASSO NÚMERO DE DOADORES DE ÓRGÃos PARA TRANSPLANTE

Roberta Marina Cioatto e Adriana de Alencar Gomes Pinheiro

Os PROGRAMAS DE INTEGRIDADE PARA CONTRATAÇÃO COM A ADMINISTRAÇÃO PÚBLICA ESTADUAL: NUDGE OU OBRIGAÇÃo LEGAL? UM OLHAR SOBRE AS DUAS PERSPECTIVAS .386

Cíntia Muniz Rebouças de Alencar Araripe e Raquel Cavalcanti Ramos Machado

Paternalismo libertário e Proteção JURídica do AMbiente: POR QUe PROTEger o AMBIENTE TAMBÉM DEVE SER PROTEGER AS LIBERDADES?

Mariana Carvalho Victor Coelho e Patryck de Araujo Ayala

Políticas PÚblicas baseadas EM EVIdÊNCIAS COMPORTAMENTAIS: REFLEXões A PARTIR do Projeto de Lei 488/2017 do Senado

Pâmela de Rezende Côrtes, André Matos de Almeida Oliveira e Fabiano Teodoro de Rezende Lara

III. ECONOMIA COMPORTAMENTAL: VIESES COGNITIVOS E POLÍTICAS PÚBLICAS .455

ECONOMIA COMPORTAMENTAL E DIREITO: A RACIONALIDADE EM MUDANÇA Marcia Carla Pereira Ribeiro e Victor Hugo Domingues

VIESES COGNITIVOS E DESENHO DE POLÍTICAS PÚBLICAS 
A neurociênCia da moralidade na tomada de DeCisões Jurídicas Complexas e No DESENHO DE POLÍTICAS PÚBLICAS

Erik Navarro Wolkart

Desvio de CARÁter ou SIMPLESMENTE HUMANO? ECONOMIA COMPORTAMENTAL APLICADA AO COMPORTAMENTO DESONESTO

Diana Orghian, Gabriel Cabral, André Pinto e Alessandra Fontana

Políticas Públicas e a ConcretizaÇão de direitos sociais: TOMAdA DE DECisão, ARQUITETURA DE ESCOLHAS E EFETIVIDADE

Ana Elizabeth Neirão Reymão e Ricardo dos Santos Caçapietra

BEHAVIORAL ECONOMICS E DIREITO DO CONSUMIDOR: NOVAS PERSPECTIVAS PARA O ENFRENTAMENTO DO SUPERENDIVIDAMENTO .568

Samir Alves Daura

A EDUCAÇÃo FORMAL PARA O CONSUMO É GARANTIA PARA UMA PRESENÇA REFLETIDA DO CONSUMIDOR NO MERCADO? UMA ANÁLISE COM BASE NA BEHAVIORAL LAW AND ECONOMICS (ECONOMIA COMPORTAMENTAL) 600

Marcia Carla Pereira Ribeiro e Edson Mitsuo Tiujo

LIBET, DETERMINISMO E CONSUMO: AS INFLUÊNCIAS DO MARKETING E A RELEVÂNCIA DA DELIBERAÇÃo CONSCIENTE NA SUPERAÇÃo CONDICIONAL DE HÁBITOS DE CONSUMO PERIGOSOS616 Émilien Vilas Boas Reis e Leonardo Cordeiro de Gusmão

CiÊNCIA DO DIREITO TRIBUTÁRIO, ECONOMIA COMPORTAMENTAL E EXTRAFISCALIDADE. .640 Hugo de Brito Machado Segundo

IV. CoMportamento JUdiCiAL: INFLUÊNCIA DE FATORES EXTRAJURÍDicos .660

FATORES METAPROCESSUAIS E SUAS INFLUÊNCIAS PARA A FORMAÇÃo DA DECISÃo JUDICIAL .662 Rogério Roberto Gonçalves de Abreu, Lúcio Grassi de Gouveia e Virgínia Colares

“A VIDA COMO ELA É": COMPORTAMENTO ESTRATÉGICO NAS CORTES Patrícia Perrone Campos Mello

A COMPOSIÇÃo do ÓRGão COLEGIAdo E SEUS EFEITOS NA TOMADA DE DECISÃo .720 André Garcia Leão Reis Valadares

Das 11 ilhas ao centro do arquipélago: os superpoderes do Presidente do STF DURANTE O RECESSO JUDICIAL E FÉRIAS .741 José Mário Wanderley Gomes Neto e Flávia Danielle Santiago Lima 
RAZÃo, EMOÇÃo E DELIBERAÇÃO: AS ADEQUAÇÕES REgIMENTAIS do SUPERIOR TribUNAL DE JUSTIÇA PARA A FORMAÇÃo DE PRECEDENTES EFICAZES

Peter Panutto e Lana Olivi Chaim

Heurística de ancoragem e fiXaÇÃo de danos morais em JUizados especiais Cíveis no Rio DE JANEIRO: UMA NOVA ANÁLISE 778

Fernando Leal e Leandro Molhano Ribeiro

LA PROTECCIÓN DE LOS DERECHOS POLÍTICOS FRENTE A LAS FUNCIONES DISCIPLINARIAS DE LAS AUTORIDADES ADMINISTRATIVAS: SUBSIDIARIEDAD Y DEFERENCIA EN EL SISTEMA INTERAMERICANO DE DERECHOS HUMANOS Jorge Ernesto Roa Roa

V. A influênCia do gÊNERo no PROCESSO DECisório JUdiCial

Como os Juízes decidem os Casos de estupro? ANALISANDo SENTENÇAS SOb A PERSPECTIVA DE VIESES E ESTEREÓTIPOS DE GÊNERO 826 Gabriela Perissinotto de Almeida e Sérgio Nojiri

GÊNERO E COMPORTAMENTO JUDICIAL NO SUPREMO TRIBUNAL FEDERAL: OS MINISTROS CONFIAM MENOS EM RELATORAS MULHERES?

Juliana Cesario Alvim Gomes, Rafaela Nogueira e Diego Werneck Arguelhes

Hércules, Hermes e a Pequena Sereia: uma reflexão sobre estereótipos de gênero, SUBPRESENTAÇÃo DAS MULHERES NOS TRIBUNAIS E (I)LEGITIMIDADE DEMOCRÁTICA DO PODER JUDICIÁRIO. .878 Jane Reis Gonçalves Pereira e Renan Medeiros de Oliveira

Prisão Cautelar de gestantes: análise do Fundamento filosófico da decisão do Habeas CoRpus N. 143.641 912

Artur César Souza e Giovania Tatibana de Souza

VI. Neurodireito APlicado ao direito E Ao Processo PENAL....................................926

CÉREbros QUe PUNEM: UMA REVISÃo CRÍTICA DA NEURoCIÊNCIA DA PUNIÇÃo .....................928 Ricardo de Lins e Horta

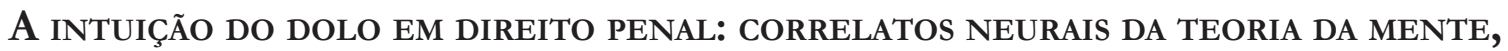
RACIOCÍNIO INDUTIVO E A GARANTIA DA CONVICÇÃO JUSTIFICADA. .946 Thiago Dias de Matos Diniz e Renato César Cardoso

As COMUNIDADES EPISTÊMICAS PENAIS E A PRODUÇÃo LEGISLATIVA EM MATÉRIA CRIMINAL..... 961 Stéphane Enguéléguélé 
DELINQUÊNCIA JUVENIL: RELAÇÕES ENTRE DESENVOLVIMENTO, FUNÇÕES EXECUTIVAS E COMPORTAMENTO SOCIAL NA ADOLESCÊNCIA .

André Vilela Komatsu, Rafaelle CS Costa e Marina Rezende Bazon

Límites TEMPORALES A LAS PENAS PRIVATIVAS DE LIBERTAD ATENDIENDO AL DESARROLLO PSICOSOCIAL.

Silvio Cuneo Nash

NEURolaw E AS PERSPECTIVAS PARA UMA ANÁLISE OBJETIVA DO COMPORTAMENTO SUGESTIONADO: REPERCUSSÃO DAS FALSAS MEMÓRIAS NA ESFERA PENAL

Mariana Dionísio de Andrade, Marina Andrade Cartaxo e Rafael Gonçalves Mota

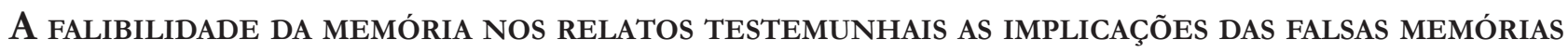
NO CONTEXTO DOS CRIMES CONTRA A DIGNIDADE SEXUAL

Caroline Navas Viana

A (IR)REPETIBILIDADE dA PROVA PENAL DEPENDENTE DA MEMÓRIA: UMA DisCUSSÃo COM BASE NA PSICOLOGIA DO TESTEMUNHO. 1058

William Weber Cecconello, Gustavo Noronha de Avila e Lilian Milnitsky Stein 


\title{
Políticas públicas em suicídio: do paternalismo clássico ao paternalismo libertário e nudging*
}

\author{
Public policies on suicide: from classic to \\ libertarian paternalism and nudging
}

\author{
Davi de Paiva Costa Tangerino** \\ Gabriel Cabral*** \\ Henrique Olive $e^{* * *}$
}

\section{Resumo}

Os índices dos eventos de suicídio vêm, progressivamente, aumentando em todo o mundo, demandando de entes públicos a implementação de medidas quanto à implementação de medidas efetivas para coibi-los. As políticas públicas tradicionalmente utilizadas, como a inserção de barreiras físicas em hotspots ou a promoção de campanhas de conscientização, não costumam apresentar resultados satisfatórios, apesar do alto custo de implementação. Tendo em vista esse contexto, pretende-se neste artigo promover uma via alternativa de intervenção. Para isto, em primeiro lugar, debate-se a via do nudging, sua forma de operação e o paternalismo de Estado; em segundo, debruça-se sobre os elementos concretos do fenômeno, realizando análises e cruzamentos de dados do Ministério da Saúde do Brasil e do Instituto Brasileiro de Geografia e Estatística, bem como utilizando estudos específicos nacionais e estrangeiros para a identificação de características e padrões dos eventos suicidas; em seguida, debatem-se as experiências estrangeiras em relação ao desenvolvimento e à aplicação de políticas públicas em seu enfrentamento. Com essas informações, discutimos medidas em forma de nudges para a gestão do fenômeno do suicídio, com a pretensão de promover o método e incentivar novas propostas de políticas públicas para esses e outros problemas na esfera da gestão pública.

Palavras-chave: Paternalismo de Estado. Nudge. Paternalismo Libertário. Políticas Públicas. Epidemiologia. Suicídio.

\section{Abstract}

The rates of suicide events have been steadily increasing all over the world, requiring public authorities to make decisions regarding the implementation of effective preventive strategies. Traditionally, interventions undertaken by policymakers such as the installation of physical barriers in hotspots or the promotion of awareness campaigns do not usually present satisfactory results despite the ensuing high cost. With that in mind, this article intends to promote nudging as an alternative course of intervention. 
Firstly, debating its process and state paternalism in general. Following that, we focus on the concrete elements of the phenomenon, analyzing and cross-checking data from the Brazilian Ministry of Health and the Brazilian Institute of Geography and Statistics, as well as using specific Brazilian and foreign studies to identify characteristics and patterns of suicidal events. Thus, we also discuss public policies' assessment about the issue of suicide in other countries. Based on this information, we explore nudging measures as suicide prevention efforts, looking to promote this alternative and its use in future public policies proposals on suicide and other matters in the sphere of public management.

Keywords: State Paternalism. Nudge. Libertarian Paternalism. Public Policies. Epidemiology. Suicide.

\section{INTRODUÇÃO}

Às vezes agimos contra nosso próprio bem-estar: compramos o que não podemos pagar, deixamos de guardar dinheiro para o futuro, comemos mais do que devemos e até mesmo atentamos contra nossas próprias vidas. Isto leva à pergunta: devemos ser protegidos de nós mesmos? Caso a resposta seja positiva, a quem deve incumbir essa proteção?

Essas perguntas se mostram ainda mais inquietantes quando o tema é suicídio, gerando enormes questionamentos acerca da ingerência estatal, de origem moral e/ou religiosa, na esfera mais íntima do indivíduo e seu desejo de viver ou morrer.

Em meio a esse dilema, os casos de suicídio vêm aumentando de forma muito significativa tanto em países com altos índice, como naqueles em que o fenômeno tradicionalmente não se apresentava como um problema mais agudo. Frente a isto, como os Estados devem reagir e em que medida podem/devem promover ações de contenção do fenômeno?

Inúmeras políticas públicas têm sido desenvolvidas no sentido de dificultar ou impedir o ato de suicídio, em especial com base em uma concepção médica, quase unânime, que enxerga no suicida um comportamento necessariamente patológico; posicionamento acompanhado, a título de exemplo, pela jurisprudência brasileira ${ }^{1}$. Com base nisto, pergunta-se: por que não se utilizar (e como fazê-lo), de nudges para promover essa opção política de proteger os indivíduos com ideações suicidas, ainda que de forma complementar a eventuais outras medidas?

Essa é a pergunta que norteia o presente trabalho, de modo que respondê-la perpassa necessariamente por alguns passos, quais sejam: i) debater o paternalismo de Estado e a terceira via dos nudges; ii) conhecer adequadamente fenômeno do suicídio; iii) verificar, com base em sua adequada compreensão, a necessidade, adequação e eficiência da utilização de nudges nesse caso concreto; e, por fim, iv) sugerir algumas medidas dessa natureza para o problema específico.

Por fim, é imprescindível alertar que este trabalho não visa a exaurir o tema de políticas públicas voltadas

\footnotetext{
1 A título de exemplo, veja-se: “isto, porque, longe de demonstrar que não pretende fugir, a atitude do paciente de atentar contra sua própria vida revela desespero e certo desequilíbrio que poderão comprometer o bom andamento da instrução criminal” (TJRJ: HC 0059130-96.2012.8.19.0000, $2^{a}$ Câmara Criminal, 18/12/2012); “a depressão embota os sentidos, tolhe a percepção, dificulta a compreensão, desorienta e abate moralmente os que são por ela acometidos, a ponto de muitos cometerem o suicídio" (TJRJ: ACR 0043099-79.2004.8.19.0000, $3^{\text {a } C a ̂ m a r a ~ C r i m i n a l, ~ 15 / 03 / 2005) ; ~ " r e i t e r a d a s ~ t e n t a t i v a s ~ d e ~ s u i c i ́ d i o, ~ o ~ q u e ~ r e f o r c ̧ a ~ a ~ n e c e s s i d a d e ~}$ de o mesmo ser mantido segregado como forma de garantir a sua própria integridade física e psicológica” (TJES: HC 000154070.2012.8.08.0000, 1a Câmara Criminal, 11/07/2012). Evidencia também este posicionamento o sistemático reconhecimento de responsabilidade civil do Estado por suicídio de pessoas sob custódia do sistema de justiça criminal (STJ: AgRg no AG 1307100/ PR, Primeira Turma, rel. Min. Sérgio Kukina, 24/10/2014; STJ: Resp 847.687/GO, Primeira Turma, rel. Min. Teori Zavascki, 17/10/2006; STJ: EDcl no AgRg no REsp 1305259, Segunda Turma, rel. Min. Mauro Campbell Marques, 15/08/2013; STF: ARE em RE 700927/GO, Segunda Turma, rel. Min. Gilmar Mendes, 28/08/2012; STF, este caso em hospital psiquiátrico: ARE em RE 691744, Segunda Turma, rel. Min. Celso de Mello, 28/08/2012).
} 
para o enfrentamento do quadro de suicídios no Brasil. Em verdade, tem por objetivo demonstrar e promover o modo de operação de políticas públicas baseadas em nudges; e, naturalmente, a publicizar e debater mais detalhadamente os elementos do fenômeno do suicídio para além dos centros de pesquisas médicas e de outras áreas afins. Dito isto, é possível adentrar ao primeiro passo, o paternalismo de Estado.

\section{SOBRE O PATERNALISMO}

\subsection{Definição de paternalismo}

Em 2013, o então prefeito de Nova Iorque, Michael Bloomberg, ao propor um limite para o tamanho de copos de refrigerantes, polarizou opiniões: de um lado, foi criticado por estar restringindo a liberdade de escolha; de outro, foi aplaudido por estar tomando medidas de redução de sobrepeso dos nova-iorquinos. A discussão acerca dos limites do Estado na conciliação de valores, que em determinados contextos tornam-se inconciliáveis — liberdade de escolha e bem-estar —, faz referência ao eixo temático do Paternalismo de Estado.

Contudo, diferentemente do caso de Nova Iorque, opções políticas com teor paternalista não são facilmente perceptíveis; entretanto, ainda que percebidas, sua complexidade dificulta sua compreensão dentro de um contexto polarizado. Em alguns casos, a dicotomia liberdade/paternalismo é notória, como em reformas trabalhistas quanto à autonomia para negociação ou, no caso de vedação, a disposição de saleiros em mesas de restaurantes; em outros, o teor paternalista pode apresentar-se de modo mais sutil, como o estabelecimento de preço mínimo para cigarros nos termos da Lei 12.546/2011, com a finalidade de dificultar o acesso ao produto danoso.

Portanto, questiona-se: quais elementos em regulamentações podem caracterizar uma política paternalista? E, por conseguinte, qual a definição de paternalismo de Estado? Comecemos pela segunda.

Sua definição é especialmente complicada, afinal, sob um aspecto prático, uma regulamentação tida como paternalista pode ter comprometida sua aceitação perante a opinião pública. O termo é percebido por alguns autores como uma ofensa ao substrato ideológico liberal típico do Estado Moderno ${ }^{2}$. Entretanto, por vezes busca-se atenuar esse posicionamento ${ }^{3}$. A título de exemplo, pode ser menos desgastante defender a obrigatoriedade do uso de cinto de segurança em razão da redução de gastos com saúde pública do que sob a alegação de que as pessoas precisam ser protegidas de sua negligência.

John Stuart Mill, considerado o fundador do eixo temático do (combate ao) paternalismo, asseverou:

seu próprio bem [do indivíduo], seja físico ou moral, não é justificação suficiente [para intervenção estatal]. Ele não pode ser legitimamente compelido a fazer ou tolerar porque isso será melhor para ele fazer deste modo, porque o fará mais feliz, porque, na opinião de outros, fazer deste modo seria sábio, ou até correto ${ }^{4}$.

Desde seu nascedouro, a discussão acerca do paternalismo tem latente o engajamento de autores libe-

2 FEINBERG, J. Harm to self: the moral limits to the criminal law. Oxford: Oxford University Press, 1986. v. 3. p. 23; VANDEVEER, D. Paternalistic intervention: the moral bounds of benevolence. Princeton: Princeton University Press, 1986. p. 4-5; ANDERSON, E. What is the point of equality? Ethics, v. 109, n. 2, p. 287-337, 1999. p. 301-302.

3 Esta afirmação pode ser constatada pelo esforço de alguns autores para recorrer a justificativas não paternalistas, como fez Seana Siffrin em relação à unconscionability doctrine do direito contratual americano, segundo a qual juízes podem a recusar a ordem de cumprimento de contratos abusivos. Outro exemplo é o de Elizabeth Anderson em relação à defesa das contribuições compulsórias para seguro de saúde e de aposentadoria (SHIFFRIN, S. V. Paternalism, unconscionability doctrine, and accommodation. Philosophy and Public Affairs, v. 29, n. 3, p. 205-250, 2000; ANDERSON, E. What is the point of equality? Ethics, v. 109, n. 2, p. 287-337, 1999.). 4 MILL, J. S. On liberty. London: Floating Express, 2009. p. 18, tradução livre, [original de 1859]. 
rais contra ingerência do Estado sobre esfera individual. Nesse sentido, a discussão costuma ter caráter propositivo, às vezes panfletário, de estabelecimento de limites para a atuação estatal. Como aponta Gerald Dworkin, as definições de paternalismo são desenvolvidas contextualmente, de acordo com o propósito do autor quanto à limitação ou liberdade de atuação estatal ${ }^{5}$.

Ainda assim, o núcleo semântico do conceito de paternalismo é limitado e costuma transitar em torno de outros conceitos específicos. Vejamos alguns exemplos de conceituação, adaptados e padronizados para observarem a seguinte formulação: $X$ age paternalisticamente em relação a $Y$ se fizer ou deixar de faz̧er Z:

1) $X$ age em relação a $Y$ paternalisticamente se interferir na liberdade ou autonomia de $Y$, sem o consentimento de $\mathrm{Y}$, apenas em razão do aumento do bem-estar, ou de alguma forma de promoção de interesses, valores ou o bem de $\mathrm{Y}^{6}$;

2) X age em relação a $Y$ paternalisticamente se pretende fechar alguma opção que estaria de outra forma aberta a Y ou escolhe para Y uma situação em que $\mathrm{Y}$ é incapaz de escolher por si mesmo. X o faz, em alguma medida, para promover o bem de $\mathrm{Y}^{7}$;

3) $\mathrm{X}$ age em relação a $\mathrm{Y}$ paternalisticamente na medida em que $\mathrm{X}$, para assegurar o bem de $\mathrm{Y}$ como um fim, impõe-se sobre $Y^{8}$;

4) $\mathrm{X}$ age em relação a $\mathrm{Y}$ paternalisticamente ao restringir a liberdade de $\mathrm{Y}$ ou ao desconsiderar as preferências atuais de $\mathrm{Y}$, desde que o faça primariamente considerando o bem de $\mathrm{Y}$ e que as ações de $\mathrm{X}$ sejam uma violação de uma regra moral ou que $\mathrm{X}$ reconheça que suas ações sobre $\mathrm{Y}$ precisam de justificação moral';

5) X $\mathrm{X}$ age em relação a $\mathrm{Y}$ paternalisticamente ao restringir a liberdade de $\mathrm{Y}$ ou ao desconsiderar as preferências atuais de $\mathrm{Y}$, desde que o faça primariamente considerando o bem de $\mathrm{Y}^{10}$;

6) X age em relação a Y paternalisticamente ao substituir o julgamento de $\mathrm{Y}$ em questão dentro da esfera de ação legítima de Y, desde que esta substituição seja direcionada aos interesses de Y em áreas que estão legitimamente dentro do controle de $\mathrm{Y}$ e que $\mathrm{X}$ considere seu julgamento sobre os interesses de $\mathrm{Y}$, em algum grau, superior ao de $\mathrm{Y}^{11}$.

É possível notar a recorrência de conceitos como liberdade, autonomia e bem-estar. Contudo, apesar de contribuírem para delimitar o sentido do conceito de paternalismo, para a circunscrição de um núcleo de sentido, não o esclarecem inteiramente, como explicam Le Grand e New:

outra razão para a falta de consenso [sobre o conceito de paternalismo] é que as pessoas inevitavelmente perceberão e interpretarão palavras em modos sutilmente diferentes, particularmente quando [se tratar de] termos abstratos como liberdade, autonomia, bem (good) e consentimento ${ }^{12}$.

Ainda que um conceito abstrato próximo aos exemplos apresentados seja capaz de acomodar intuições linguísticas pessoais, tal conceito não se mostra operacional, ou seja, não serve como instrumento para se identificar paternalismo em uma situação concreta. Uma vez que é possível o conflito de interpretações

5 DWORKIN, G. Defining paternalism. In: COONS, C.; WEBER, M. Paternalism: theory and practice. Cambridge: Cambridge University Press, 2013. p. 26.

6 DWORKIN, G. Paternalism: some second thoughts. In: SARTORIUS, R. Paternalism. Minneapolis: University of Minnesota Press, 1983.

7 CLARKE, S. A definition of paternalism. Critical Review of International Social and Political Philosophy, v. 5, n. 1, p. 81-91. 2002.

8 KLEINIG, J. Paternalism. Manchester: Manchester University Press, 1983.

9 GERT, B.; CULVER, C. The justification of paternalism. Ethics, v. 89, n. 2, p. 199-210, jan. 1979.

10 POPE, T. M. Counting the Dragon's Teeth and Claws: the definition of hard paternalism. Georgia State University Law Review, v. 20, n. 3, p. 659-722, 2004.

11 SHIFFrIN, S. V. Paternalism, unconscionability doctrine, and accommodation. Philosophy and Public Affairs, v. 29, n. 3, p. 205, 2000.

12 LE GRAND, J.; NEW, B. Government paternalism: nanny State or helpful friend? Princeton: Princeton University Press, 2015. p. 8, tradução livre. 
entre o indivíduo destinatário da política paternalista e seu promotor, mostra-se complicada a identificação com segurança de que se está diante de uma manifestação de paternalismo.

Para superar essa dificuldade, suscitada por Le Grand e New, e tornar o conceito operacional, propõe-se fazer um refinamento em relação aos conceitos previamente apresentados: deslocar o foco do conceito para as motivações de quem pratica o paternalismo. Desse modo, consideramos que bastam somente duas condições concomitantes para que se interprete algo como paternalista: que o promotor (i) identifique uma falba na cognição do indivíduo e, baseado nesta identificação, (ii) aja para aumentar o bem-estar deste indivíduo ${ }^{13}$. Portanto, não são relevantes a percepção do destinatário e a efetivação do bem desejado pelo promotor.

\subsection{Paternalismo de Estado}

Essas condições, enquanto caracterizadoras de paternalismo, encontram respaldo até mesmo na obra do antipaternalista Stuart Mill, por atuarem como critérios para o estabelecimento de limites a seu princípio do dano. Por este princípio, a intervenção do Estado apenas se justifica se o destinatário causar danos a terceiro. Porém, Mill prevê uma exceção, situação em que é possível a intervenção destinada a impedir que o indivíduo cause dano a si próprio. Entretanto, apenas se justifica caso seja atendida a condição de atribuição de capacidade cognitiva ao destinatário. Isto é, que exista a crença do interventor de que o indivíduo não tenha conhecimento suficiente quanto aos riscos; porém, havendo conhecimento desse risco, nada pode fazer o interventor além de alertar. A título de exemplo, o caso da ponte:

se um agente público ou qualquer outra pessoa vir uma pessoa tentando atravessar uma ponte que seja considerada perigosa, e não tenha tempo para avisá-la do perigo, podem impedi-la sem nenhuma real violação a sua liberdade; [...] não obstante, quando não se tem certeza [do perigo da ponte], mas apenas há o perigo de descuido da pessoa, ninguém além dela pode fazer este julgamento [...]. Neste caso, ela deve ser apenas alertada ${ }^{14}$.

Nesse caso, empurrar o indivíduo que não sabe do perigo é legítimo, pois o indivíduo não tem informações suficientes para a tomada de decisão. O limite para a intervenção se baseia na existência de percepção do interventor quanto à assimetria de capacidade cognitiva entre as partes. Afinal, se não há atribuição de inferioridade cognitiva seguida de uma ação de substituição de julgamento, não há paternalismo.

Essa concepção explica o porquê de, por exemplo, a persuasão racional, a disponibilização de informações ou a promoção de campanhas educativas não serem intuitivamente assimiladas como paternalistas. Nesses casos, não parece haver uma identificação de falha cognitiva de uma parte em relação à outra. Se há a tentativa de persuasão, há a expectativa de que o outro seja capaz de assimilar os argumentos e realizar por si só o que é melhor para si.

Apesar de o critério defendido neste artigo para identificação de paternalismo ser sólido diante de um caso concreto, esse critério evidencia um problema particular da própria conceituação de paternalismo, especialmente o de Estado: nem sempre é possível distinguir motivações reais de motivações manifestas. Por exemplo, mensagens em embalagens de cigarros são paternalistas?

De acordo com a conceituação simplificada que aqui se defende, a resposta é: depende. É possível que se tenha uma resposta diferente caso se considere a justificação oficial em comparação com uma análise da justificação mais razoável. Vejamos as possibilidades de justificação oficial: (i) as figuras como representação imagética da informação, a substituir ou complementar a textual, de danos do cigarro à saúde individual; (ii)

13 Essa concepção está em consonância com a de diversos outros autores, como Le Grand e New (LE GRAND, J.; NEW, B. Government paternalism: nanny State or helpful friend? Princeton: Princeton University Press, 2015. p. 23), em que pese apontarem também a existência de um incremento no bem-estar como uma condição necessária; e Sarah Conly, que afirma "[...] no paternalismo há uma substituição de julgamento; uma parte assume que o que você precisa é maior do que seu próprio julgamento" (CONLY, S. Against autonomy: justifying coercive paternalism. Cambridge: Cambridge University Press, 2013. p. 36, tradução livre). 14 MILL, J. S. On liberty. London: Floating Express, 2009. p. 163-164, tradução livre, [original de 1859]. 
as figuras como indicação de que há danos coletivos decorrentes do uso de cigarro, como aumento de gastos com Saúde Pública; (iii) as figuras como meio para chocar, para que pessoas associem o fumo de cigarro àquelas realidades ilustradas. Nesse contexto, apenas a justificação (iii) teria cunho paternalista, haja vista que não visa a convencer os fumantes, mas, a assustá-los, a considerar seu bem-estar.

A despeito de qual seja a justificação oficial exposta por órgãos públicos, parece razoável acreditar que o objetivo das figuras seja, de fato, chocar. Por essas razões, ela é paternalista, pois seu planejador diagnosticou um problema cognitivo nas pessoas: elas não seriam capazes de racionalmente assimilar informações e precisariam de uma intervenção extrema para agir em benefício de seu bem-estar.

Identificar uma política como paternalista, como se percebe, é uma tarefa que exige alguma reflexão, que pode se estender ao fato de que o paternalismo não necessariamente busca afetar diretamente eventuais resultados, podendo em realidade almejar interferir na crença das pessoas. Nesse sentido, Cass Sunstein compilou algumas formas de atuação de políticas paternalistas:

(1) afetar os resultados sem afetar as ações e crenças das pessoas; (2) afetar as ações sem influenciar as crenças; (3) afetar as crenças para poder influenciar as ações; ou (4) afetar as preferências, independentemente de afetar as crenças, para influenciar as ações ${ }^{15}$.

Talvez o ponto mais controverso seja o (3): afetar crenças por meio de campanhas educacionais, como cita Sunstein. Ensinar pessoas, a princípio, como argumentamos, não é paternalista. Pode ser paternalista, contudo, se houver referência a um tipo de paternalismo, o paternalismo moral.

Além disto, outra distinção importante se dá entre paternalismo de meios e de fins ${ }^{16}$. De acordo com essa distinção, o paternalismo pode ser direcionado (i) às decisões intermediárias, ou seja, aquelas que as pessoas fazem para atingir certos fins, ou (ii) para os próprios fins. Uma forma de entender esse mecanismo, ainda que não se trate de um exemplo de paternalismo, é o funcionamento de um aplicativo de navegação de trânsito: o aplicativo restringe-se a informar qual a forma mais eficiente (meio) para que seu operador possa chegar ao destino escolhido (fim).

Uma linha divisória entre meios e fins, contudo, pode ser tênue. Nesse sentido, o exemplo dado por Le Grand e New:

[...] desenvolvendo uma justificação para uma política que pretende dissuadir pessoas de fazerem sexo com múltiplos parceiros, é importante estar claro se pretendemos ajudar pessoas a evitar risco excessivo para sua saúde (relacionado a meios) ou considerar errado em si mesmo possuir diversos parceiros sexuais (paternalismo relacionado a fins) ${ }^{17}$.

Nesse exemplo, o paternalismo de fins trata de uma questão relacionada, especificamente, a valores morais, não a bem-estar em um sentido amplo. Isto nos remete a mais uma distinção relevante da discussão sobre paternalismo: entre paternalismo moral, como o caso acima, e moralismo legal. De acordo com Dworkin, moralismo legal trata de previsão legal de proibição de condutas que sejam consideras imorais, mesmo que não sejam danosas, ao passo que paternalismo moral trata de prevenir o dano moral que a pessoa possa causar a si mesma ${ }^{18}$. Nesse caso, a atribuição de falha cognitiva diz respeito à incapacidade de uma pessoa perceber que está se degradando moralmente.

O paternalismo moral está em uma zona limítrofe do conceito de paternalismo, pois trata não de bem-estar, mas de correção moral. Assim, a menos que se considere que estar moralmente melhor também signifique estar com mais bem-estar, paternalismo moral não pode ser considerado uma forma incontroversa de paternalismo ${ }^{19}$.

15 SUNSTEIN, C. Why nudge?: the politics of libertarian paternalism. New Haven: Yale University Press, 2014. p. 53, tradução livre.

16 SUNSTEIN, C. Why nudge?: the politics of libertarian paternalism. New Haven: Yale University Press, 2014. p. 21.

17 LE GRAND, J.; NEW, B. Government paternalism: nanny State or helpful friend? Princeton: Princeton University Press, 2015.

p. 30, tradução livre.

18 DWORKIN, G. Moral paternalism. Law and Philosophy, v. 24, n. 3, p. 305-319, 2005.

19 LE GRAND, J.; NEW, B. Government paternalism: nanny State or helpful friend? Princeton: Princeton University Press, 2015. 


\subsection{Paternalismo libertário}

Além dessa controvérsia relacionada à identificação de bem-estar com moralidade, situações em que não exista um conflito necessário entre restrição de liberdade e aumento de bem-estar também causam dissonância de opiniões. Será possível conceber uma forma de paternalismo que concilie liberdade e aumento de bem-estar? De acordo com Thaler e Sunstein, proponentes do paternalismo libertário, essa aproximação não é apenas possível, mas uma sofisticação da atuação estatal. Para os autores, essa conciliação ocorre com base em "[...] uma abordagem que preserva a liberdade de escolha, mas autoriza instituições públicas e privadas a dirigir pessoas em direções que promoverão seu bem-estar"20.

A ideia de "dirigir pessoas em direções que promoverão seu bem-estar" parece fazer referência a tecnologias de atuação estatal e pressupostos teóricos estranhos à tradicional discussão sobre paternalismo. De fato, o debate tradicional tem como objeto as ferramentas à disposição de planejadores de políticas públicas que podiam ser, de um lado, claramente paternalistas: proibições ou incentivos fiscais; de outro, claramente liberais: campanhas de conscientização e disponibilização de informações.

Em comum, adotam como pressuposto a Teoria Econômica Neoclássica, que aposta na capacidade das pessoas de tomar decisões de forma racional, lógica, consistente e autointeressada. O modelo de comportamento humano adotado por essa corrente econômica para análise e predição de decisões é o do homo economicus. Conforme este modelo, as análises econômicas partem de pressupostos de que seres humanos são seres essencialmente racionais: analisam fatos, probabilidades, custos e benefícios para fazer escolhas e agem, consistentemente, com o resultado de sua análise. Conforme Stuart Mill: "[...] é preocupado consigo somente como um ser que deseja possuir riquezas, e que é capaz de julgar a eficácia comparativa de meios para obter este fim" 21 .

A partir desse pressuposto, justificam-se as opções disponíveis ao debate tradicional sobre paternalismo. A opção liberal, de conscientização e disponibilização de informação, justifica-se pela presunção de que más decisões decorrem de falta de informação. Em mesmo sentido, a opção paternalista, de proibições e incentivos fiscais, justifica-se pela presunção de que as pessoas tomarão decisões consistentes com um exame prévio em relação aos custos da decisão.

Essas presunções vêm sendo alvo de críticas, em especial por economistas comportamentais, que tentam demonstrar a falta de realismo psicológico da corrente econômica neoclássica ${ }^{22}$. A economia comportamental tem o mérito de aproximar teorias econômicas, tradicionalmente abstratas e teoréticas, de evidências em psicologia do comportamento. A mudança mais relevante talvez seja a percepção de que não somos tão racionais quanto imaginávamos ou como retratavam — e ainda retratam — modelos econômicos, haja vista que temos nossa racionalidade limitada (bounded rationality).

O conceito de racionalidade limitada foi introduzido de forma crítica por Herbert A. Simon no artigo A Behavioral Model of Rational Choice (1955). Para Simon, a própria ideia de determinar qual a opção mais racional é um tipo de custo que a torna irracional: conseguir as informações e calcular os prós e contras etc. geram custos à ação. Tendo em vista esse claro prejuízo, afirma que as pessoas em realidade se contentam com as opções "boas o suficiente" (“good enough”), que são as mais racionais diante de nossas limitações ${ }^{23}$. Como destaca Simon, (i) falta-nos tempo para refletir; (ii) nem sempre temos acesso a todas as informações

p. 35.

20 THALER, R.; SUNSTEIN, C. Libertarian paternalism. American Economic Review, v. 93, n. 2, p. 175-179, may 2003. p. 179, tradução livre.

21 MILL, J. S. Essays on some unsettled questions of political economy. Kitchener: Batoche Books, 2000. p. 97, tradução livre [Original de 1844].

22 JOLLS, C.; SUNSTEIN, C.; THALER, R. A behavioral approach to law and economics. Stanford Law Review, v. 50, p. 1471 1550, 1998.

23 SIMON, H. A behavioral model of rational choice. Quarterly Journal of Economics, v. 69, n. 1, p. 99-118, feb. 1955. 
necessárias; e (iii) nosso cérebro tem limitações computacionais. Além dessas limitações percebidas por Simon, sofremos de um problema cognitivo mais recentemente constatado: (iv) os vieses da cognição ${ }^{24}$.

Esses vieses da cognição são padrões de comportamento que se desviam de um padrão lógico e racional. Nesse sentido, afirma-se que o "erro de julgamento [um viés] é demonstrado pela comparação entre a resposta das pessoas ou com um fato estabelecido [...] ou com regras aceitas de aritmética, lógica ou estatística" 25 . Assim, pode-se inferir que, para identificar um viés da cognição, deve-se, em primeiro lugar, identificar um parâmetro baseado naquelas regras; posteriormente, testar as pessoas para descobrir se elas respondem sistemática, previsível e diferentemente da resposta prevista pelo parâmetro. Em Thinking fast and slow, Kahneman traz estudos discutindo vieses da cognição; conforme expõe, uma boa explicação para o fato de sermos potencialmente tão racionais, mas agirmos tão irracionalmente, é a existência de dois sistemas de cognição, os sistemas 1 e 2: sistemas intuitivo e reflexivo, respectivamente. Esses sistemas são ativados e solicitados em situações diferentes: quando uma pessoa está aprendendo a dirigir, ela o faz usando o sistema 2. Depois de muita prática, ela começa a dirigir "no automático", usando o sistema 1. As diferenças entre os sistemas vão muito além do tipo de gatilho que os ativa, conforme a Quadro $1^{26}$.

Quadro 1 - Sistema 1 versus Sistema 2


of Economic Literature, v. 150, n. 2, p. 351-401, 2002. 
iniciais que podem ser arbitrárias ${ }^{29}$; e a aversão à perda, isto é, a tendência para valorizar, desproporcionalmente, as perdas em relação aos ganhos ${ }^{30}$.

Com os diversos estudos sobre vieses da cognição, percebe-se que (i) pessoas agem irracionalmente de forma sistemática e previsível e (ii) pequenas intervenções, mesmo as mais sutis, podem fazer a diferença para neutralizar os efeitos negativos dos vieses. Assim, se os erros são previsíveis e pequenas intervenções podem anulá-los, há uma possibilidade de ser paternalista, ajudando pessoas a cometerem menos erros que diminuam seu bem-estar, por meio de pequenas e sutis intervenções. Essas intervenções preservam a liberdade de escolha do indivíduo ${ }^{31}$, afinal são direcionadas à arquitetura da decisão. Nesse sentido, Thaler e Sunstein:

paternalismo libertário é um tipo relativamente fraco, suave e não intrusivo de paternalismo porque escolhas não são bloqueadas, retiradas ou significativamente dificultadas. Se as pessoas querem fumar cigarros, comer muitos doces, escolher um plano de saúde ruim, ou deixar de guardar dinheiro para a aposentadoria, paternalistas libertários não as forçarão a fazer diferente — ou fazer as coisas muito mais difíceis para elas ${ }^{32}$.

Como complementam, "a regra de ouro é assumir que "tudo tem importância"’33. Cada pequeno detalhe da arquitetura da decisão interfere, em algum grau, na tomada de decisão: a cor da caneta usada, a altura das cadeiras, a temperatura do ambiente, o teor dos quadros nas paredes, a ordem das frases, a limpeza do local etc. Cada elemento tem diferentes tipos e intensidades de efeitos de acordo com a forma como são apresentados, mesmo que a arrumação não tenha sido intencional. Por exemplo, um estudo aponta que pessoas estão mais dispostas a comer maçãs em ambientes com iluminação amarela do que azul ${ }^{34}$.

A possibilidade de alteração de comportamentos por meio de pequenas e sutis alterações na arquitetura da decisão, chamados de nudges (empurrõezinhos), é um pressuposto central ao paternalismo libertário.

\subsubsection{Nudges}

Richard Thaler e Cass Sunstein trazem dois conceitos independentes entre si. Primeiro, afirmam que:

é qualquer aspecto da arquitetura da decisão que altera o comportamento das pessoas de forma previsível sem proibir nenhuma opção ou alterar significativamente seus incentivos econômicos. [Esta] intervenção precisa ser simples e fácil de evitar. Nudges não são ordens. Botar a fruta na altura dos olhos conta como um nudge. Banir comida não saudável (junk food), não ${ }^{35}$.

29 TVERSKY, A.; KAHNEMAN, D. Judgment under uncertainty: heuristics and biases. Science, v. 185, n. 4157, p. 1124-1131, sep. 1974. p. 1128-1130.

30 TVERSKY, A.; KAHNEMAN, D. Advances in prospect theory: cumulative representation of uncertainty. Journal of Risk. and Uncertainty, v. 5, p. 297-323, 1992.

31 Segundo Mitchell, Thaler e Sunstein estariam apenas parcialmente corretos ao afirmar que o paternalismo libertário preserva a liberdade (MITCHELL, G. Libertarian paternalism is an oxymoron. Northwestern University Law Review, v. 9, n. 3, p. 1245-1277, 2005.). Há dois tipos de liberdade: a "negativa", que indica indica a ausência de algum obstáculo para a decisão livre, isto é, ser uma "liberdade de" (from); e a "positiva", que indica a presença de autonomia, isto é, uma "liberdade para" (to) (BERLIN, I. Two concepts of liberty. In: BERLIN, I. Four essays on liberty. Oxford: Oxford University Press, 1969. p. 6-8, traduções livres [original de 1958]). Nudges, por alterarem a arquitetura de decisão, de fato, não criam obstáculos significativos para a tomada livre de decisão (liberdade negativa), mas acabam por influenciá-la de tal forma que relativizam o grau de autonomia (liberdade positiva) do tomador de decisão. Em consonância com esta ideia, um estudo recente indicou que pessoas que creem menos em sua autonomia e autodeterminação avaliam nudges mais favoravelmente (HANNIKAINEN, I et. al. A deterministic worldview promotes approval of state paternalism. Journal of Experimental Social Psychology, v. 70, p. 251-259, may 2017.).

32 THALER, R.; SUNSTEIN, C. Nudge: improving decisions about health, wealth and happiness. New Haven: Yale University Press, 2008. p. 5, tradução livre.

33 THALER, R.; SUNSTEIN, C. Nudge: improving decisions about health, wealth and happiness. New Haven: Yale University Press, 2008. p. 3, tradução livre.

34 YANG, L.; CHO, S.; SEO, H. Effects of light color on consumers: acceptability and willingness to eat apples and bell peppers. Journal of Sensory Studies. v. 31, n. 1, p. 3-11, nov. 2016.

35 THALER, R.; SUNSTEIN, C. Nudge: improving decisions about health, wealth and happiness. New Haven: Yale University Press, 2008. p. 6, tradução livre. 
Porém, em seguida, afirmam que "nudge é qualquer fator que, significativamente, altere o comportamento de Humanos, mas que seria ignorado por Econs [homens econômicos]"36.

É possível conciliar essas duas definições? Para alguns autores, nudges, além de serem pequenas intervenções na arquitetura da decisão, precisam ser direcionados às intuições do sistema 1, ignorando apelos à reflexão do sistema $2^{37}$. Nesse sentido, nudges envolvem a manipulação de falhas de cognição, de maneira que sejam manejadas em favor do tomador de decisão. Portanto, os vieses da cognição são aliados dos planejadores de políticas públicas ${ }^{38}$.

De fato, o que torna os nudges genuínos é a ideia de explorar deficiências cognitivas e motivacionais das pessoas de forma paternalista ${ }^{39}$, afinal sempre existiram pequenas intervenções na arquitetura da decisão — como a disposição de placas informativas ou incentivos econômicos —, porém sem a abordagem cientificista na referida exploração.

Essa interpretação mais restrita não parece ser a adotada pelos próprios criadores do termo, como esclarece o próprio Sunstein, segundo o qual definições mais restritas estão equivocadas em, pelo menos, dois aspectos:

primeiro, o universo dos nudges é bem mais amplo [...]. Paternalismo libertário inclui intervenções (como avisos e regras default) que [...] não precisam especificamente neutralizar (counteract) vieses e inadequações decisionais. Segundo, a palavra "neutralizar" é melhor do que "explorar". Nudges podem neutralizar vieses (como otimismo irrealista) sem explorar nada ${ }^{40}$.

Portanto, nudge seria um termo amplo, que engloba diversas intervenções, inclusive aquelas que não se baseiam em ou pretendem neutralizar vieses da cognição; não são intrusivos ${ }^{41}$. Sequer precisam fazer menção a descobertas da psicologia ou economia comportamental, como nos exemplos de disponibilização de informações, lembretes ou avisos.

Para tentar organizar e dar consistência à miríade de exemplos, Robert Baldwin, considerou dividir os nudges em três graus, de acordo com o impacto na autonomia dos indivíduos. As ideias dos autores podem ser resumidas no Quadro 02.

36 THALER, R.; SUNSTEIN, C. Nudge: improving decisions about health, wealth and happiness. New Haven: Yale University Press, 2008. p. 8, tradução livre.

37 BOVENS, L. The ethics of nudge. In: GRÜNE-YANOFF, T.; HANSON, S. Preference change: approaches from philosophy, economics and psychology. Berlin: Springer, 2009. Cap. 10, p. 209; JOHN, P.; SMITH, G.; STOKER, G. Nudge nudge, think think: two strategies for changing civic behaviour. Political Quarterly, v. 80, n. 3, p. 361-370, july 2009; REBONATO, R. Taking liberties: a critical examination of libertarian paternalism. Houndmills: Palgrave Macmillan, 2012. p. 84; CALO, R. Code, nudge, or notice? Iowa Law Review, v. 99, n. 2, p. 773-802. 2014. p. 784; HANSEN, P. The definition of nudge and libertarian paternalism: does the hand fit the glove? The European Journal of Risk Regulation, v. 7, n. 1, p. 155-174, mar. 2016. p. 162.

38 GRÜNE-YANOFF, T.; HERTWIG, R. Nudge versus boost: how coherent are policy and theory? Minds and Machines, v. 26, n. 1, p 149-183, 2016. p. 170.

39 GRÜNE-YANOFF, T.; HERTWIG, R. Nudge versus boost: how coherent are policy and theory? Minds and Machines, v. 26, n. 1, p 149-183, 2016. p. 154.

40 SUNSTEIN, C. Why nudge?: the politics of libertarian paternalism. New Haven: Yale University Press, 2014. p. 59, tradução livre.

41 FERREIRA, F.; POTTUMATI, E. A licitação pública como instrumento de desenvolvimento na perspectiva do paternalismo. Revista Brasileira de Politicas Públicas, v. 4, n. 1, p. 201-213, jan./jun. 2014. p. 210-211. 
Quadro 2 - Tradução da Tabela “Three Degrees of Nudge” (Três graus de Nudges).

\begin{tabular}{|l|l|l|l|}
\hline Grau de Nudge: & Características típicas: & Exemplos: & Impacto na autonomia: \\
\hline Primeiro & $\begin{array}{l}\text { Simples informações ou } \\
\text { lembretes, com o objeti- } \\
\text { vo de aumentar a capaci- } \\
\text { dade das pessoas de fazer } \\
\text { uma escolha informada, } \\
\text { racional e consciente. }\end{array}$ & $\begin{array}{l}\text { 1. Alerta em maços de } \\
\text { cigarro. } \\
\text { 2. Lembrete para pre- } \\
\text { encher a declaração de } \\
\text { imposto. }\end{array}$ & $\begin{array}{l}\text { Respeita a autonomia e } \\
\text { aumenta a racionalidade } \\
\text { do tomador de decisão. }\end{array}$ \\
\hline $\begin{array}{l}\text { Limitações comporta- } \\
\text { mentais ou volitivas são } \\
\text { exploradas de forma a } \\
\text { influenciar decisões em } \\
\text { uma direção escolhida. }\end{array}$ & $\begin{array}{l}\text { 1. A instituição de um } \\
\text { regime opt-out de doação } \\
\text { de órgãos. } \\
\text { 2. Alteração da área } \\
\text { destinada a atividade } \\
\text { fumante para longe da } \\
\text { área de trabalho. }\end{array}$ & $\begin{array}{l}\text { O tomador de decisão po- } \\
\text { deria, ao refletir, descobrir } \\
\text { a natureza e o efeito do } \\
\text { nudge - mas é improvável } \\
\text { que o faça em razão das } \\
\text { limitações comportamen- } \\
\text { tais e tendência a exibir } \\
\text { respostas "automáticas". }\end{array}$ \\
\hline Terceiro & $\begin{array}{l}\text { Estratégias de framing, } \\
\text { respostas emocionais ou } \\
\text { técnicas dissimuladas são } \\
\text { usadas para influenciar } \\
\text { decisões ou preferências. }\end{array}$ & $\begin{array}{l}\text { 1. Uma campanha que } \\
\text { promova hábitos ali- } \\
\text { mentares saudáveis com } \\
\text { slogan: “Don't lose your } \\
\text { looks, junk the junk food!”. } \\
\text { 2. [...] utilização de fo- } \\
\text { tografias de vítimas de } \\
\text { câncer de pulmão para } \\
\text { controlar o fumo. }\end{array}$ & $\begin{array}{l}\text { O tomador de decisão } \\
\text { é influenciado, mas a } \\
\text { reflexão é obstruída ou } \\
\text { materialmente falha para } \\
\text { extensão da influência do } \\
\text { comportamento ou da } \\
\text { preferência. }\end{array}$ \\
\hline
\end{tabular}

Fonte: Baldwin (2014, p. 838, tradução livre).

Essa tabela tem uma função didática, pois esquematiza diversos exemplos em categorias bem definidas. Como pode ser notado, há nudges que incentivam decisões mais racionais (primeiro grau); outros, que não as incentivam, mas podem ser desvendados (segundo grau); e, por fim, aqueles que não as incentivam e também não podem ser descobertos por reflexão (terceiro grau) ${ }^{42}$. Com base nesta classificação, nudges de segundo e terceiro grau têm algo em comum: não incentivam decisões mais racionais, mas contornam essa tentativa, substituindo a decisão racional da pessoa objeto da política por artifícios baseados em estudos comportamentais. Por sua vez, nudges de primeiro grau se diferenciam, substancialmente, dos demais quanto ao grau de atribuição à capacidade de cognição das pessoas. Nudges de primeiro grau, portanto, não são paternalistas.

Antes de debater, especificamente, o tratamento do Estado quanto ao suicídio, é importante conhecer esse fenômeno, analisando índices e locais de ocorrência, quem o realiza e quais são os métodos utilizados, de modo que se possa em seguida discutir, de forma segura, a necessidade e adequação na tomada de decisões e direcionamento de políticas públicas quanto ao fenômeno do suicídio.

42 BALDWIN, R. From regulation to behaviour change: giving nudge the third degree. Modern Law Review, v. 77, n. 6, p. 831-857, 2014. p. 837. 


\section{Características do suicídio no Brasil em perspectiva com a Realidade mundial}

\subsection{Introdução metodológica}

Para conhecer o fenômeno do suicídio no país, é importante utilizar as estatísticas produzidas em âmbito federal pelo Ministério da Saúde do Brasil (MS) e inseridas no Sistema de Informações de Mortalidade (SIM), que é composto pelo "conjunto de ações relativas à coleta, codificação, processamento de dados, fluxo, consolidação, avaliação e divulgação de informações sobre os óbitos no país” "43. Em síntese, os óbitos são avaliados por profissionais de saúde de forma padronizada (por meio da Declaração de Óbito [DO]) de acordo com os parâmetros estabelecidos internacionalmente na Classificação Internacional de Doenças (CID), sendo possível alcançar especificações quanto às causas da morte, como também seu local e características do indivíduo falecido. A título de exemplo, nos termos da CID-10, um caso de suicídio pode ser classificado como "lesão autoprovocada voluntariamente > autointoxicação por e exposição, intencional, a analgésicos, antipiréticos e antirreumáticos".

Ainda assim, por mais que exista no Brasil essa sistematização integrada desde 1976 , não se evita a subnotificação dos eventos suicidas e, consequentemente, a incapacidade dos dados de representar absolutamente a realidade.

Os problemas perpassam desde casos de desconhecimento de óbito pelo sistema de saúde em função de sepultamentos clandestinos ${ }^{45}$ a desconhecimento e desatenção de agentes de saúde, que por vezes preenchem, incorretamente ${ }^{46}$ ou de forma ilegível ou incompleta, as DOs ${ }^{47}$.

Em específico quanto às DOs produzidas em Instituto Médico Legal, responsável pelo exame em casos de suspeita de suicídio, também foram relatados problemas quanto às informações, ainda que em regra sejam mais confiáveis ${ }^{48}$.

Mas o fenômeno da subnotificação não se limita ao Brasil, é mundial, ainda que com maior incidência em países menos desenvolvidos ${ }^{49}$.

43 BRASIL. Ministério da Saúde. Secretaria de Vigilância em Saúde. Portaria n. 116, de 11 de fevereiro de 2009. art. $1^{\circ}$.

44 HECKMANN, I. C. et al. Análise do preenchimento de declarações de óbitos em localidade do Estado do Rio Grande do Sul (Brasil). Revista de Saúde Pública, São Paulo, v. 23, n. 4, p. 292-297, 1989. p. 292.

45 LOVISI, G. et al. Prevalência de transtornos mentais nas tentativas de suicídio em um hospital de emergência no Rio de Janeiro. Cadernos de Saúde Pública, Rio de Janeiro, v. 25, n. 9, p. 2064-2074, set. 2009; FAÇANHA, M. et al. Busca ativa de óbitos em cemitérios da Região Metropolitana de Fortaleza, 1999 a 2000. Epidemiologia e Serviços de Saúde, v. 12, n. 3, p. 131-136. p. 133.

46 HECKMANN, I. C. et al. Análise do preenchimento de declarações de óbitos em localidade do Estado do Rio Grande do Sul (Brasil). Revista de Saúde Pública, São Paulo, v. 23, n. 4, p. 292-297, 1989. p. 293; SCHNITMAN, A. Análise da fidedignidade da declaração de causa básica de morte por câncer em Salvador, Brasil. Revista de Saúde Pública, v. 24, n. 6, p. 490-496, 1990. p. 492; VANDERLEI, L. et al. Avaliação da confiabilidade da causa básica de óbito em unidade terciária de atenção à saúde materno-infantil. Informe Epidemiológico do SUS, v. 11, n. 1, p. 15-23, 2002. p. 19-20; TURRINI, R.; SANTO, A. Infecção hospitalar e causas múltiplas de morte. Jornal de Pediatria, v. 78, n. 6, p. 485-490, 2002. p. 487; LAURENTI, R. et al. Informação em mortalidade: o uso das regras internacionais para a seleção da causa básica. Revista Brasileira de Epidemiologia, v. 12, n. 2, p. 195-203, 2009. p. 198; BARBUSCIA, D.; RODRIGUES-JÚNIOR, A. Completude da informação nas Declarações de Nascido Vivo e nas Declarações de Óbito, neonatal precoce e fetal, da região de Ribeirão Preto, São Paulo, Brasil, 2000-2007. Cadernos de Saúde Pública, Rio de Janeiro, v. 27, n. 6, p. 1192-1200, jun. 2011. p. 1195.

47 SILVA, J. A. et al. Declaração de óbito, compromisso no preenchimento: avaliação em Belém - Pará, em 2010. Revista da Associação Médica Brasileira, v. 59, n. 4, p. 335-340, 2013. p. 337-338.

48 JORGE, M. H. P. M. Situação atual das estatísticas oficiais relativas à mortalidade por causas externas. Revista de Saúde Pública, São Paulo, v. 24, n. 3, p. 217-223, 1990. p. 221; SIMÕES, E.; REICHNHEIM, M. Confiabilidade das informações da causa básica nas declarações de óbito por causas externas em menores de 18 anos no Município de Duque de Caxias - RJ. Cadernos de Saúde Pública, Rio de Janeiro, v. 17, n. 3, p. 521-531, 2001. p. 528; SOUZA, E.; MINAYO, M. C.; CAVALCANTE, F. G. O impacto do suicídio sobre a morbimortalidade da população de Itabira. Ciência \& Saúde Coletiva, v. 11, n. Sup., p. 1333-1342, 2007. p. $1337-1338$. 49 AVANCI, R. et al. Perfil do adolescente que tenta suicídio em uma unidade de emergência. Revista Brasileira de Enfermagem, v. 58, n. 5, p. 535-539, set./out. 2005. p. 536; PRITCHARD, C.; HEAN, S. Suicide undetermined deaths among youths and young adults in Latin America comparison with the 10 major developed countries: a source of hidden suicides? Crisis, v. 29, n 2, p. 145- 
Enquanto há locais com seríssimas limitações no próprio sistema de produção de registros, como Paquistão ${ }^{50}$, China ${ }^{51}$ e Índia ${ }^{52}$, também há outros, como o Brasil, em que se verificam problemas na constatação da causa de morte, em especial com confusões entre suicídio e causas "indeterminada" ou "acidente", como o exemplo relatado por pesquisadores na Finlândia acerca da confusão entre acidentes de carros e suicídios em automóveis ${ }^{53}$.

Ou seja, diversos são os problemas inseridos nas estatísticas de mortalidade por meio das DOs, mas, apesar disto, ainda são o melhor instrumento para compreender esse fenômeno no país. Entretanto, não bastam esses dados, sendo necessário inseri-los em conjuntos populacionais, fornecidos no país pelo Instituto Brasileiro de Geografia e Estatística (IBGE). Neste estudo, utilizam-se os dados de anos censitários conforme os censos e, nos demais, conforme as projeções populacionais mais recentes decorrentes da aplicação do Método das Componentes Demográficas ${ }^{54}$.

Com o cruzamento de dados do SIM e do IBGE, é possível alcançar dados essenciais para o estabelecimento de estratégias, como: i) dados populacionais de regiões, estados ou municípios, incluindo detalhes quanto ao sexo e faixa etária; também ii) dados detalhados quanto aos óbitos, incluindo causa da morte, sexo e idade do falecido, local e data de ocorrência.

\subsection{A dimensão e características dos eventos suicidas}

O suicídio é um evento que merece cada vez mais atenção das autoridades, sendo constatados 804.000 eventos em 2012, o que significou um suicídio a cada quarenta segundos ${ }^{55}$, representando mais de $1 \%$ de todas as mortes registradas ${ }^{56}$; em inúmeros anos seguidos tais índices se mostram superiores às mortes em guerras e homicídios somados ao redor do mundo ${ }^{57}$. A título de exemplo, nos Estados Unidos, foi a décima causa de morte segundo o relatório nacional de estatísticas vitais, lançado pelo Centers for Disease Control and Prevention (CDC), representando 1,6\% de todas as mortes no país ${ }^{58}$.

No Brasil, os índices de suicídio são ainda inferiores em comparação com a maioria de outros países, entretanto isto não significa a inexistência de um problema. Como se vê no Gráfico 01, o crescimento do número de casos de suicídios em todo o país é uma constante. Foram registrados, em todo o país, 10.533 mortes por suicídio em 2013, o que representa, considerado o número de eventos, aumentos de 33,99\%, em relação ao ano de 2003 , e de $89,6 \%$, quanto a 1993. A mesma comparação quando realizada nas regiões oferece os seguintes resultados: região norte: 73,68\% e 196,48\%; região nordeste: 53,95\% e 194,45\%; região sudeste: $31,61 \%$ e $61,19 \%$; região sul: $16,33 \%$ e 56,62\%; região centro-oeste: $25,29 \%$ e $96,70 \%$.

153, 2008. p. 151.

50 KHAN, M. et al. Epidemiology of suicide in Pakistan: determining rates in six cities. Archives of Suicide Research, v. 12, n. 2, p. 155-160, 2008. p. 155.

51 WU, K.; CHEN, Y.; YIP, P. Suicide methods in Asia: implications in suicide prevention. International Journal of Environmental Research and Public Health, v. 9, p. 1135-1158, 2012. p. 1137.

52 RAJENDRA, R. et al. A feasibility study to establish a deliberate self-harm register in a state hospital in Southern India. British Journal of Medical Practioners [online], v. 8, n, 1, mar. 2015. Disponível em: < http://www.bjmp.org/content/feasibility-study-establishdeliberate-self-harm-register-state-hospital-southern-india >. Acesso em: 10 mar. 2018.

53 HERNETKOSKI, M.; KESKINEN, E.; PAKKARI, I. Driver suicides in Finland: are they different in northern and Southern Finland? International Journal of Circumpolar Health, v. 68, n 3, p. 249-260, 2009. p. 257.

54 BRASIL. Ministério do Planeamento, Orçamento e Gestão. Instituto Brasileiro de Geografia e Estatística. Projeção da população: Brasil e Unidades da Federação. Rio de Janeiro: IBGE, 2013.

55 ORGANIZAÇÃO MUNDIAL DE SAÚDE. World Health Statistics 2015. Luxemburgo: WHO Graphics, 2015. p. 22.

56 ORGANIZAÇÃO MUNDIAL DE SAÚDE. World Health Statistics 2014. Itália: WHO Graphics, 2014. p. 22.

57 MINAYO, M. C.; CAVALCANTE, F. G. Suicídio entre pessoas idosas: revisão da literatura. Revista de Saúde Pública, v. 44, n. 4, p. $750-757,2010$. p. 751.

58 UNITED STATES OF AMERICA. Department of Health and Human Services. Centers for Disease Control and Prevention. National Center for Health Statistics. National Vital Statistics Reports. Deaths: Leading Causes for 2013, v. 64, n. 2 , feb. 2016. 
Gráfico 1 - Ocorrência de suicídios em regiões do Brasil - 1993/2013, com intervalos (números absolutos).

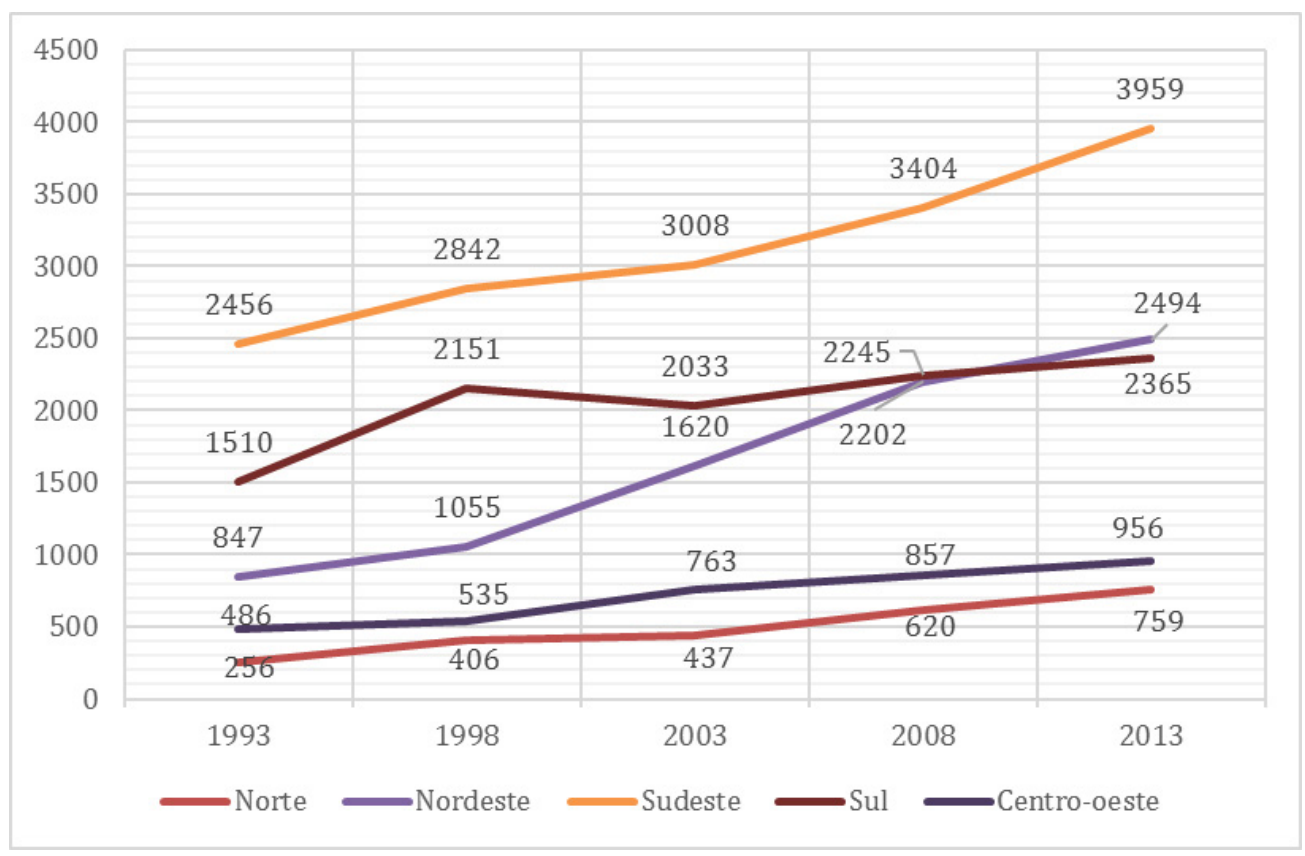

Fonte: SIMSVS/MS; IBGE.

Esses dados em desenvolvimento percentual demonstram o crescimento do convívio de um grupo populacional com eventos suicidas, de modo que se percebe no Brasil uma quantidade aproximada àquela em países como França (9.919 em 2012) e Alemanha (9.964 em 2012), que possuem as maiores quantidades de eventos na União Europeia (UE). Porém, é imprescindível lembrar que esses países possuem população significativamente menor que a brasileira e maior que a de seus vizinhos; por conta disto, deve-se trabalhar com o já referido índice TMG conforme traz o Gráfico 02, em que se percebe não ser significativamente alta a taxa de eventos no Brasil.

Gráfico 2 - Ocorrência de suicídios no Brasil e em países da União Europeia - 2011/2012 (tx/100.000 habitantes).

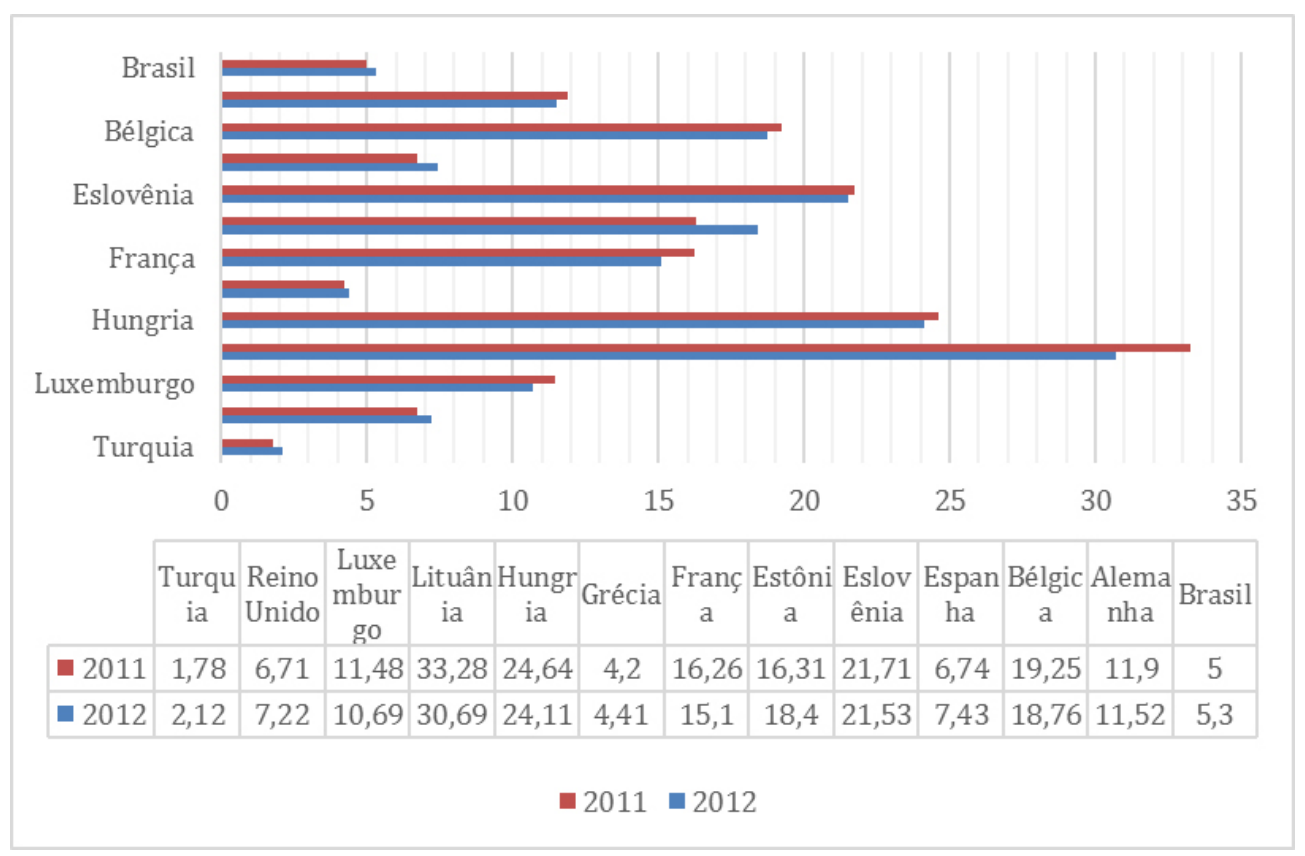

Fonte: SIM/SVS/MS; IBGE; Eurostat ${ }^{59}$.

59 Eurostat disponibiliza registros estatísticos em: <http://www.ec.europa.eu/eurostat/data/database. $>$. 
Quanto a esta, tem-se que não é uniforme se as regiões políticas são comparadas, com destaque para índices mais altos na região sul e o contínuo crescimento de registros nas regiões norte e nordeste, conforme a Tabela 03. Deve-se atentar para o fato de que os índices crescem pouco de ano em ano, mas ganham significativa representatividade em um lapso maior; um fenômeno observado em todo o mundo ${ }^{60}$.

Tabela 1 - Ocorrência de suicídios no Brasil e em suas regiões - 1993/2013, com intervalos (tx/100.000 habitantes).

\begin{tabular}{ccccccc}
\hline & Brasil & Norte & Nordeste & Sudeste & Sul & $\begin{array}{c}\text { Centro- } \\
\text { oeste }\end{array}$ \\
\hline $\mathbf{2 0 1 3}$ & 5,2 & 4,5 & 4,5 & 4,7 & 8,2 & 6,4 \\
$\mathbf{2 0 1 2}$ & 5,3 & 4,2 & 4,3 & 4,9 & 8,5 & 6,5 \\
$\mathbf{2 0 1 1}$ & 5 & 4,3 & 4,3 & 4,8 & 7,8 & 5,7 \\
$\mathbf{2 0 1 0}$ & 4,8 & 3,9 & 4 & 4,6 & 7,9 & 5,8 \\
$\mathbf{2 0 0 9}$ & 4,9 & 3,9 & 3,9 & 4,4 & 8,2 & 6 \\
$\mathbf{2 0 0 8}$ & 4,9 & 4,1 & 4,1 & 4,2 & 8,2 & 6,3 \\
$\mathbf{2 0 0 3}$ & 4,4 & 3,2 & 3,3 & 4 & 7,8 & 6,2 \\
$\mathbf{1 9 9 8}$ & 4,3 & 3,4 & 2,3 & 4,1 & 8,9 & 4,9 \\
$\mathbf{1 9 9 3}$ & 3,7 & 2,4 & 1,9 & 3,8 & 6,7 & 4,9 \\
\hline
\end{tabular}

Fonte: SIM/SVS/MS; IBGE.

\subsubsection{Gênero e método}

Quando observados especificamente por gênero, vê-se que há uma quantidade muito maior de suicídios dentre pessoas do sexo masculino no Brasil. Conforme o Gráfico 03, no ano de 2013, 78,88\% dos suicídios no Brasil foram realizados por homens; em 2012, 78,12\%; em 2011, 78,78\%; em 2010, 78,05\%; em 2005, 78,87\%; em 2004, 78,12\%; em 2003, 79,58\%. Ou seja, tem-se a constante de que, a cada dez suicídios no país, aproximadamente oito são realizados por pessoas do sexo masculino, acompanhando uma realidade mundial dentre os países que publicam as estatísticas, com exceção apenas da China ${ }^{61}$; ainda, pode-se afirmar que, proporcionalmente, o grupo mais atingido são homens idosos, haja vista, proporcionalmente, sua maior incidência frente às demais faixas etárias (Gráfico 04).

60 VÄRNIK, P. Suicide in the world. Int. J. Res. Public Health, v. 9, p. 760-771, 2012. p. 761.

61 VÄRNIK, P. Suicide in the world. Int. J. Res. Public Health, v. 9, p. 760-771, 2012. p. 763. 
Gráfico 3 - Ocorrência de suicídios por sexo no Brasil - 2003/2013 (números absolutos).

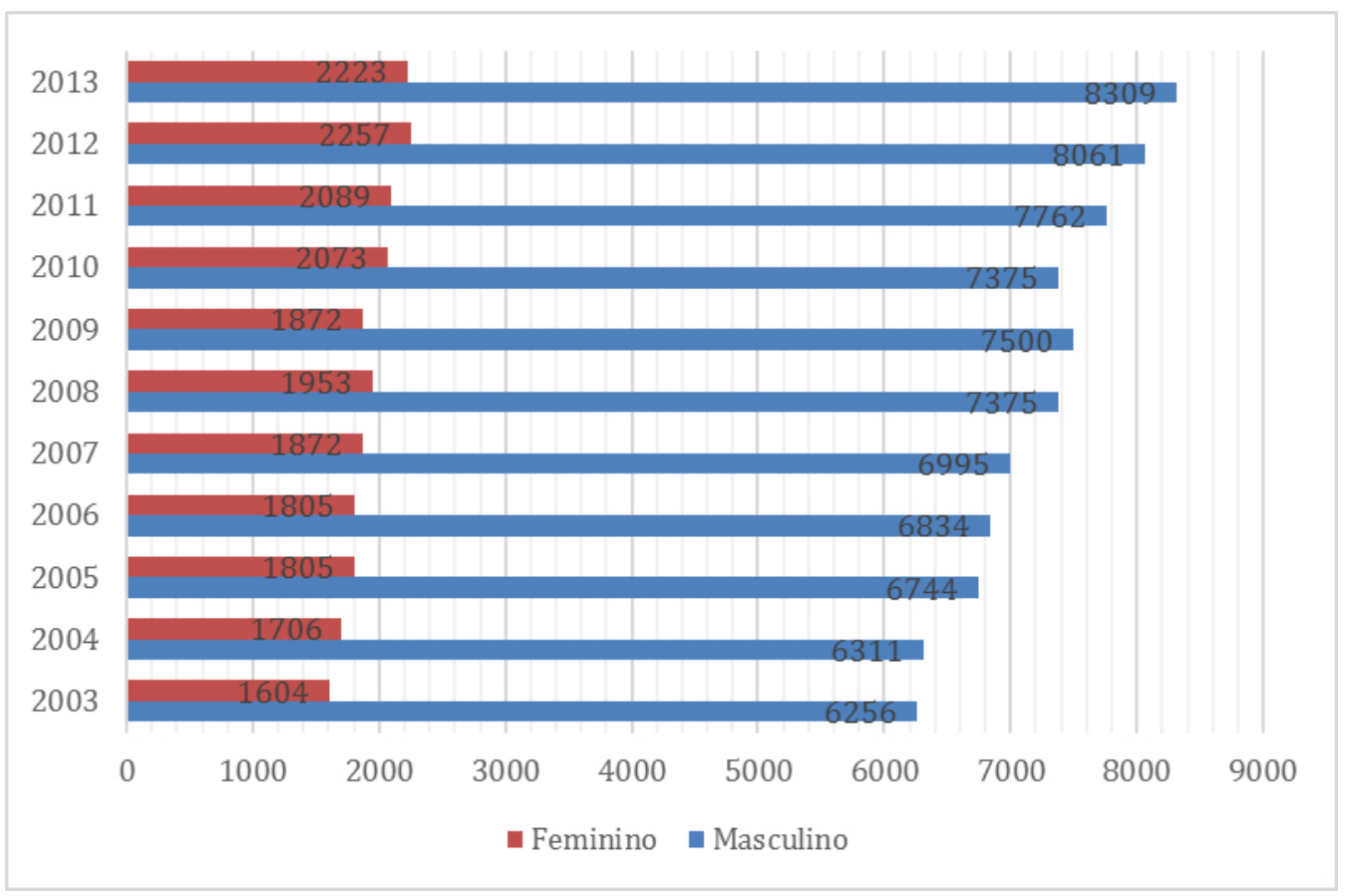

Fonte: SIM/SVS/MS; IBGE.

Gráfico 4 - Ocorrência de suicídios por idade no Brasil— 2010/2013 (tx/100.000 habitantes).

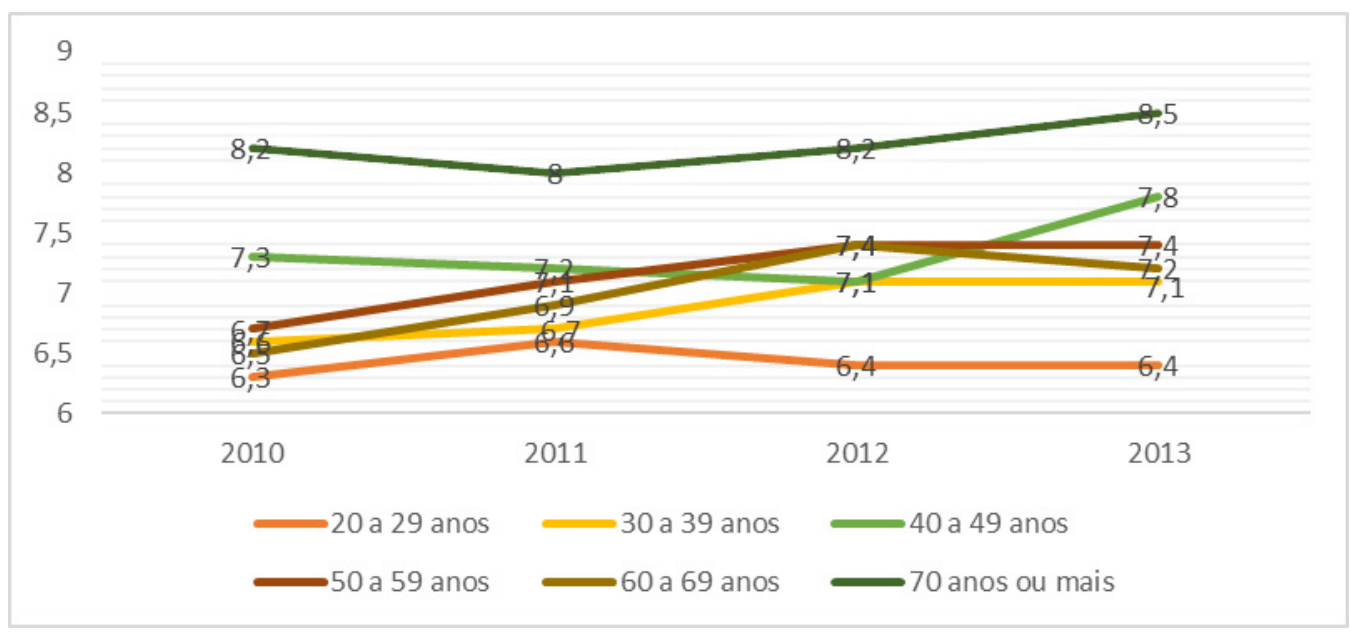

Fonte: SIM/SVS/MS; IBGE.

Ainda, a considerar que o número de mulheres no Brasil é recorrentemente um pouco maior do que o de homens, tem-se que, dentre estes, há um crescimento de eventos superior ao crescimento dentre as mulheres. Em síntese, conforme se vê no Gráfico 05, a cada dia há proporcionalmente mais homens suicidas, ainda que se permaneça a relação 4:1 em relação às mulheres, pois o crescimento populacional feminino está acima do crescimento de suicídios dentre esse sexo, proporcionalmente; o que não ocorre com o sexo masculino. Porém, tanto na China como em outros países asiáticos se percebe e prevê cada vez maior redução dessa diferençç ${ }^{62}$.

62 PHILLIPS, M.; LIU, H.; ZHANG, Y. Suicide and social change in China. Culture, Medicine and Psychiatry, v. 23, p. 25-50, 1999. p. 30; PHILLIPS, M.; LIU, H.; ZHANG, Y. Suicide and social change in China. Culture, Medicine and Psycbiatry, v. 23, p. 25-50, 1999. p. 465-466; 
Gráfico 5 - Ocorrência de suicídios por sexo no Brasil — 2000/2013 (tx/100.000 habitantes).

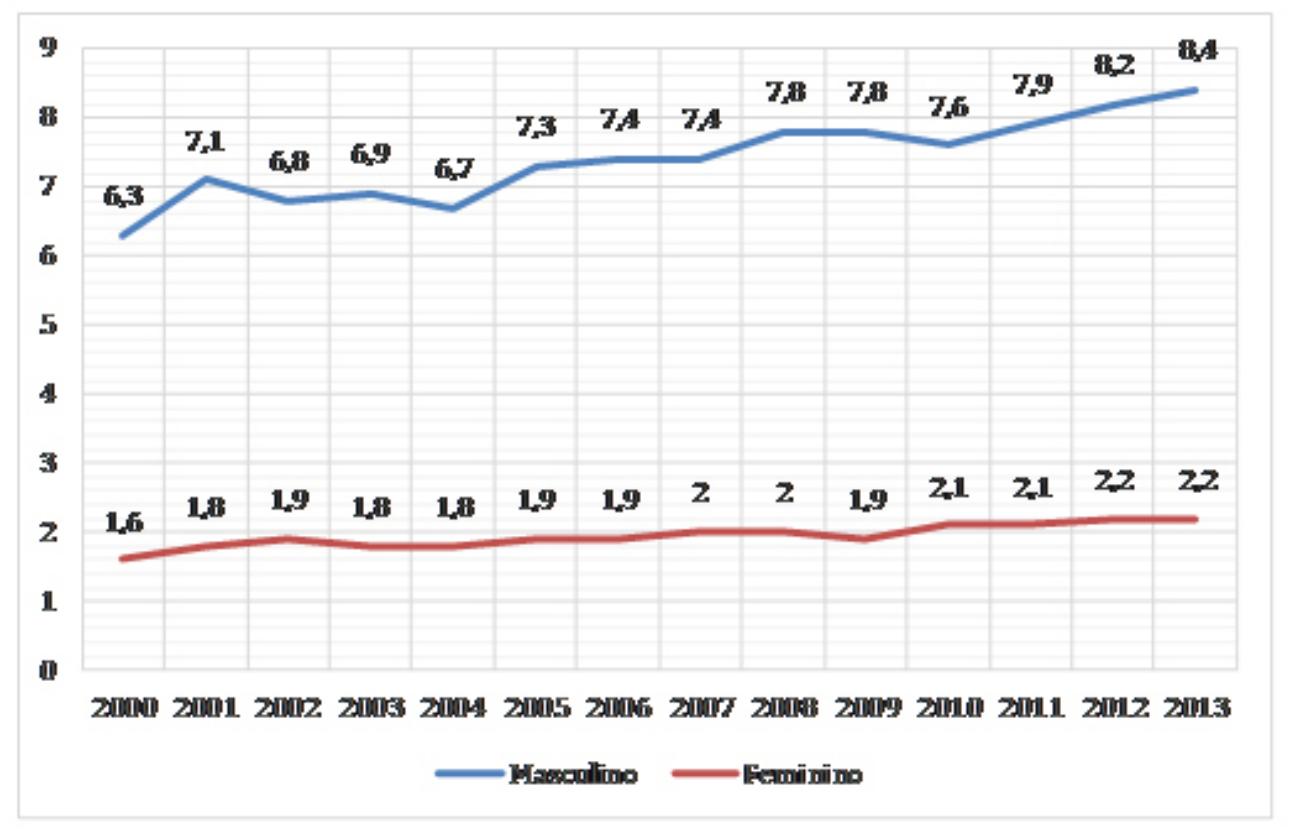

Fonte: SIM/SVS/MS; IBGE.

De qualquer modo, não é possível afirmar que o ato suicida é um evento de predominância dentre homens, afinal, em âmbito global, sabe-se que a considerar apenas as tentativas de suicídio, as estimativas são de que os índices dentre mulheres representam números muito elevados em relação a homens ${ }^{63}$, com estudos realizados em locais de atendimentos emergenciais demonstrando a maior incidência de mulheres, como, por exemplo, no Brasil ${ }^{64}$, na Alemanha ${ }^{65} \mathrm{e}^{\text {Turquia }}{ }^{66}$. Estima-se que, a cada suicídio consumado, vinte indivíduos não conseguiram fazê-lo ${ }^{67}$, o que conduz à estimativa de 16.884 .000 tentativas de suicídios no mundo no ano de 2012, que representaria uma Taxa de Tentativa Geral de 234,5 por 100.000 habitantes ${ }^{68}$.

Essa significativa diferença entre homens e mulheres parece estar atrelada ao método utilizado para a realização do suicídio, haja vista que métodos mais agressivos e letais são tipicamente masculinos ${ }^{69}$.

O uso de arma de fogo é o método mais letal dentre todos os possíveis, atingindo cerca de $90 \%$ de consumação $^{70}$. Um exemplo concreto é a realidade dos Estados Unidos, em que este foi o método prevalente, com $51,42 \%$ dos eventos em 2013, ainda que apenas 5\% dos atos suicidas e auto lesivos se utilizem desse

63 SOUZA, E.; MINAYO, M. C.; CAVALCANTE, F. G. O impacto do suicídio sobre a morbimortalidade da população de Itabira. Ciência \& Saúde Coletiva, v. 11, n. Sup., p. 1333-1342, 2007. p. 1340.

64 HESKETH, J.; CASTRO, A. Fatores correlacionados com a tentativa de suicídio. Revista de Saúde Pública, v. 12, p. 138-146, 1978. p. 145; SÁ, N. B. et al. Atendimentos de emergência por tentativas de suicídio. Revista Médica de Minas, v. 20, n. 2, p. 145-152, 2010. p. 147.

65 BREUER, H.; BREUER, J.; FISCHBACH-BREUER, B. Social, toxicological and meteorological data on suicide attempts. European archives of Psychiatry and Clinical Neuroscience, v. 235, p. 367-370, 1986. p. 368.

66 DOGANAY, Z. et al. Climatic and diurnal variation in suicide attempts in de ED. American Journal of Emergency Medicine, v. 21, n. 4, p. 271-275, july 2003. p. 272.

67 ORGANIZAÇÃO MUNDIAL DE SAÚDE. World Health Statistics 2014. Itália: WHO Graphics, 2014. p. 26.

68 É importante ressaltar que o cálculo foi feito com base na projeção da ONU para a população de 2013 (7,2 bilhões de pessoas), em sua revisão de 2012: ONU. World population prospects. The 2012 revision: comprehensive tables. New York: United Nations, 2013. v. 1.p. 1.

69 JOO, S. et al. Factors associated with suicide completion: a comparison between suicide attempters and completers. Asia-Pacific Psychiatry, v. 8, n. 1, p. 80-86, mar. 2016. p. 82.

70 SHENASSA, E.; CATLIN, S.; BUKA, S. Lethality of firearms relative to other suicide methods: a population based study. Journal of Epidemiology and Community Health, v. 57, n. 2, p. 120-124, feb. 2003. p. 123; ELNOUR, A.; HARRISON, J. Lethality of suicide methods. Injury Prevention, v. 14, p. 39-45, 2008. p. 39; BARBER, C.; MILLER, M. Reducing a suicidal person's access to lethal means of suicide: a research agenda. American Journal of Preventive Medicine, v. 47, n. 352, p. 264-272, 2014. p. 264. 
método ${ }^{71}$. No Brasil, os índices são significativamente mais baixos, tendo sido o método utilizado apenas em 9\% dos suicídios dentre os anos de 2009 e 2013; porém, conforme se vê nos gráficos 06 e 07, muito mais homens dele se utilizam em comparação a mulheres.

Gráfico 6 - Distribuição dos métodos dentre homens no Brasil - 2009/2013.

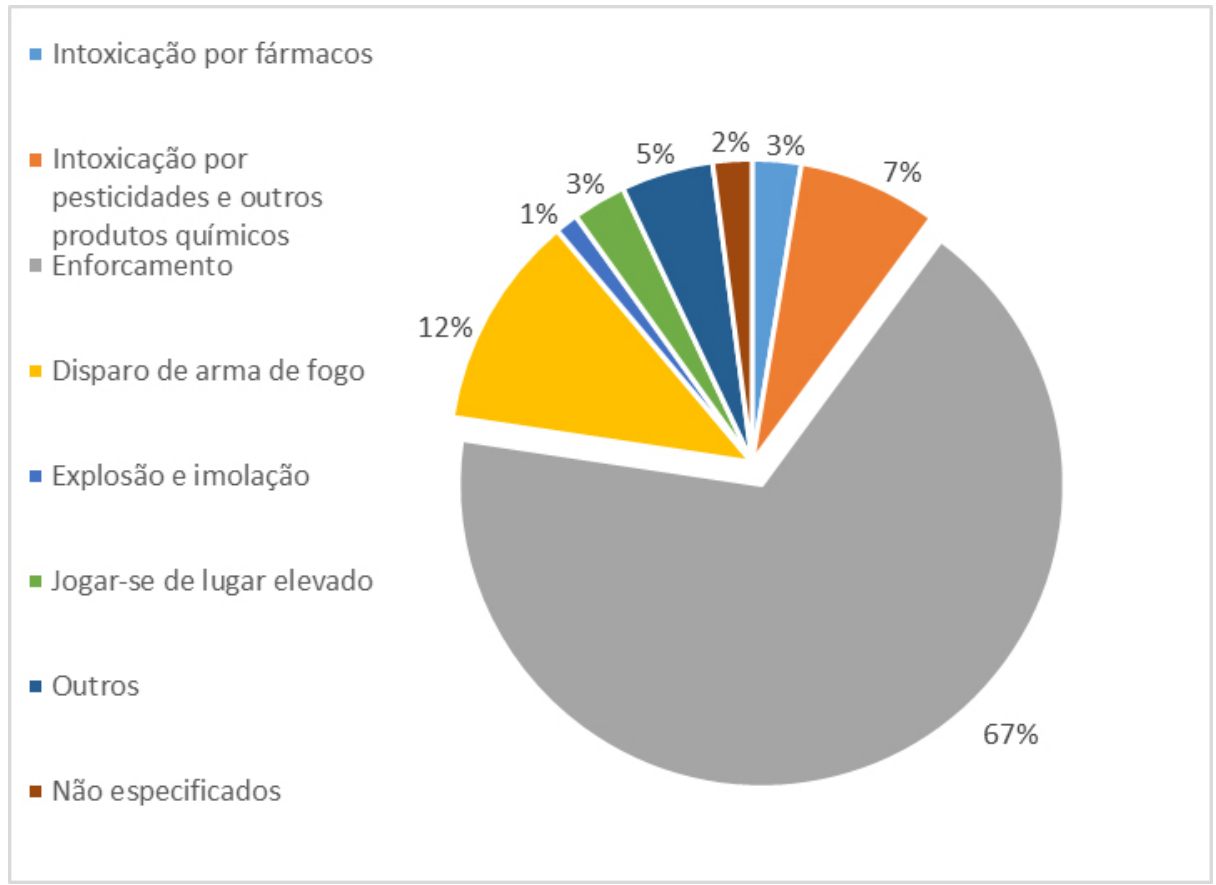

Fonte: SIM/SVS/MS.

Gráfico 7 - Distribuição dos métodos dentre mulheres no Brasil — 2009/2013.
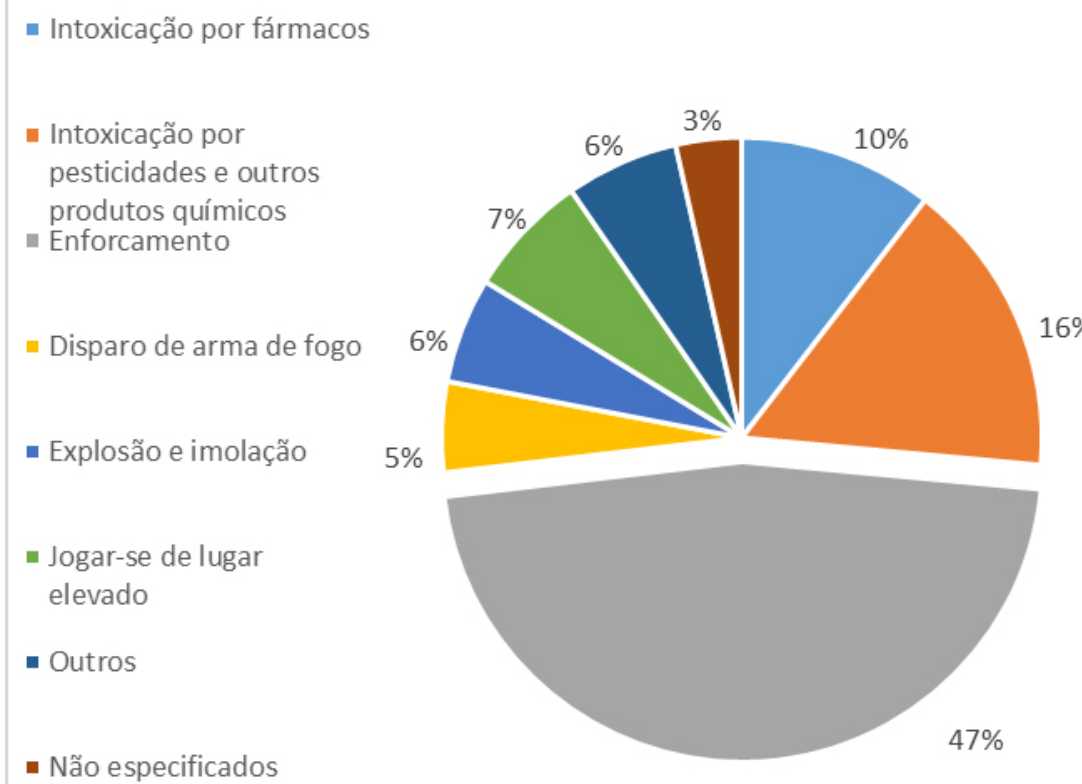

Fonte: SIM/SVS/MS.

71 UNITED STATES OF AMERICA. Department of Health and Human Services. Centers for Disease Control and Prevention. National Center for Health Statistics. National Vital Statistics Reports. Deaths: Leading Causes for 2013, v. 64, n. 2, feb. 2016. p. 84-85.

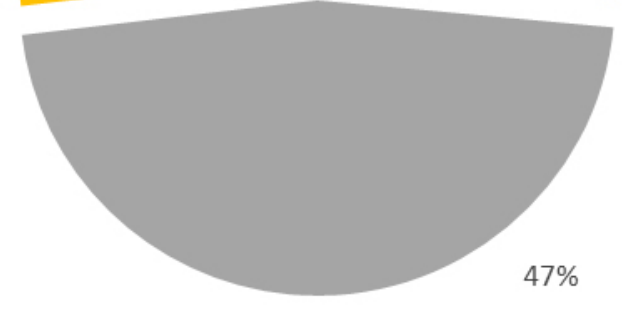


Em seguida, encontra-se o enforcamento, método preferencial para a realização de suicídio no Brasil, que possui alto grau de letalidade $-70 \%{ }^{72}$. É o método mais utilizado em diversos países asiáticos, como Arábia Saudita, Barein, Coreia do Sul, Filipinas, Irã, Tailândia, Taiwan ${ }^{73}$ e Japão ${ }^{74}$, como em países europeus, com exceção da Suíça, em que prevalece o suicídio por arma de fogo ${ }^{75}$.

Em especial quanto a mulheres, como traz o Gráfico 08, ainda que o enforcamento continue sendo o método mais utilizado, sua redução é bastante significativa, contribuindo para a explicação que atribui a utilização de métodos menos letais aos menores índices de suicídio consumados dentre mulheres. Ganha destaque nesse grupo a utilização da autointoxicação, chegando a $26 \%$ do total no período analisado.

A autointoxicação, apesar de genericamente ser método único, varia demasiadamente de acordo com o objeto utilizado para causar a morte, portanto com índice de letalidade variável, e sua utilização decorrerá fundamentalmente da acessibilidade àquele objeto.

É indiscutível que a disponibilidade é elemento central na escolha do método pelo indivíduo ${ }^{76}$. Bons exemplos podem ser obtidos a partir com base na análise do controle e restrição de armas de fogo, como na Coreia do Sul, Japão, Suécia e Taiwan, países com severas legislações de armas e irrisórios índices de suicídio por este método ${ }^{77}$. Isto pode ser ainda melhor evidenciado nos Estados Unidos ao se comparar índices entre estados com severo ou brando controle de $\operatorname{armas}^{78}$.

Em específico quanto à autointoxicação, destacam-se os países orientais, com altíssimos índices de suicídio por esse método dentre mulheres, como Paquistão ${ }^{79}$, Índia ${ }^{80}$, e o notório exemplo do Sri Lanka, que registrava em 1950 taxa de suicídio de 6,6; em 1984, 37,081; chegando a 47,0/100 mil hab. em 1995 ${ }^{82}$, com o uso de pesticidas como principal método ${ }^{83}$. O país, em 1995, adotou medidas muito restritivas ao acesso

72 GUNNEL, D. et al. The epidemiology and prevention of suicide by hanging: a systematic review. International Journal of Epidemiology, v. 34, p. 433-442, 2005. p. 433.

73 WU, K.; CHEN, Y.; YIP, P. Suicide methods in Asia: implications in suicide prevention. International Journal of Environmental Research and Public Health, v. 9, p. 1135-1158, 2012. p. 1145.

74 YOSHIOKA, E. et al. Time trends in method-specific suicide rates in Japan, 1990-2011. Epidemiology and Psychiatric Sciences, v. 25 , n. 1, p. 58-68, feb. 2016. p. 61.

75 VÄRNIK, A. et al. Suicide methods in Europe: a gender-specific analysis of countries participating in the "European Alliance Against Depression”. Journal of Epidemiology and Community Health, v. 62, p. 545-551, 2008. p. 546.

76 YIP, P. et al. Means restriction for suicide prevention. Lancet, v. 23, n. 379, p. 2393-2399, june 2012. p. 2393; BETZ, M. et al. Lethal means access and assessment among suicidal emergency department patients. Depression and Anxiety, v. 33, n. 6, p. 502-511, june 2016. p. 405-408.

77 LIN, J.; LU, T. Suicide mortality trends by sex, age and method in Taiwan, 1971-2005. BMC Public Health [online], v. 8, n. 6, jan. 2008. Disponível em: <https://bmcpublichealth.biomedcentral.com/articles/10.1186/1471-2458-8-6>. Acesso em: 13 mar. 2018 ; CHEN, Y.; PARK, N.; LU, T. Suicide methods used by women in Korea, Sweden, Taiwan and the United States. Journal of the Formosan Medical Association, v. 108, n. 6, p. 452-459, june 2009. p. 456; RUNESON, B. et al. Method of attempted suicide as predictor of subsequente successful suicide: national long term cohort study. BMJ [online], v. 341, 2010. Disponível em: <https://www.ncbi. nlm.nih.gov/pmc/articles/PMC2903664>. Acesso em: 13 mar. 2018; AHN, M. et al. Gender ratio comparisons of the suicide rates and methods in Korea, Japan, Australia, and the United States. Journal of Affective Disorders, v. 142, n. 1-3, p. 161-165, dec. 2012. p. 164. 78 ANESTIS, M.; ANESTIS, J. Suicide rates and state laws regulating access and expositure to handguns. American Journal of Public Health, v. 105, n. 10, p. 2049-2058, oct. 2015. p. 2052-2053.

79 AHMAD, R. et al. Acute poisoning due to commercial pesticides in Multan. Pakistan Journal of Medical Sciences, v. 18, n. 3, p. $227-$ 231, july/sep. 2002. p. 230; KHAN, M. et al. Suicides in the developing world: case study from Pakistan. Suicide and Life-Threatening Behavior, v. 36, n. 1, feb. 2006. p. 78.

80 BANERJEE, G. et al. The vulnerability of indian women to suicide a field-study. Indian J. Psychiatry, v. 32, n. 4, p. 305-308, oct. 1990. p. 307-308; RADHAKRISHNAN, R.; ANDRADE, C. Suicide: an indian perspective. Indian J Psycbiatry [online], v. 54, p. 304-319, 2012. Disponível em: <http://www.indianjpsychiatry.org/text.asp?2012/54/4/304/104793>. Acesso em: 13 mar. 2018. p. 306; PATEL, V. et al. Suicide mortality in India: a nationally representative survey. The Lancet, v. 379, p. 2343-2351, 2012. p. 23462347.

81 LESTER, D. Suicide in emigrants from the Indian subcontinent. Transcultural psychiatry, v. 37, n. 2, p. 243-254, 2000 . p. 248.

82 RATNAYEKE, L. Suicide and crisis intervention in rural communities in Sri Lanka: a column from befrienders international. Crisis, v. 17, n. 4, p. 149-151, 1996. p. 149.

83 WU, K.; CHEN, Y.; YIP, P. Suicide methods in Asia: implications in suicide prevention. International Journal of Environmental Research and Public Health, v. 9, p. 1135-1158, 2012. p. 1145. 
a pesticidas, contribuindo significativamente para a progressiva redução que se verificou a partir de $1998^{84}$.

Com a existência de um combate generalizado a produtos de alta toxicidade e redução a seu acesso, as autointoxicações são redirecionadas (displacement) a produtos de menor letalidade, promovendo mais tentativas do que consumações de suicídio, especialmente dentre mulheres. Entretanto, a dificuldade em promover essa limitação fica evidenciada, por exemplo, com os recorrentes relatos de autointoxicação no Brasil com o uso de proibidos "raticidas", de fácil acesso e baixo custo ${ }^{85}$.

A importância da disponibilidade de um determinado método mostra-se de forma ainda mais evidente no caso de hotsposts, ou seja, lugares que atraem suicidas tanto por seu fácil acesso como por uma mística decorrente de eventos anteriores, como por exemplo a ponte Golden Gate, que registrou quase 20 suicídios por ano entre 1937 e $1991^{86}$.

Em locais como Hong Kong e Singapura, locais em que mais de $80 \%$ da população vive em lugares elevados, jogar-se de lugar elevado (JLE) é o principal método utilizado ${ }^{87}$. No Brasil, conforme os gráficos 07 e 08, JLE seria um método pouco utilizado. Entretanto, esses dados consideram suicídios ocorrentes em inúmeros locais onde sequer há condições físicas para JLE. Portanto, para melhor demonstrar a relevância desse método, apresentam-se, na Tabela 04, índices de suicídios em algumas das grandes metrópoles brasileiras.

Tabela 2 - Suicídios por jogar-se de lugar elevado em grandes capitais brasileiras selecionadas (porcentagem específica dentre homens $[\mathrm{H}]$, dentre mulheres $[\mathrm{M}]$ e o total $[\mathrm{T}]$; tx = suicídios a cada 100 edificações na cidade).

\begin{tabular}{|c|c|c|c|c|c|c|c|c|c|c|c|c|c|}
\hline \multirow[b]{2}{*}{1} & \multicolumn{3}{|c|}{2013} & \multicolumn{3}{|c|}{2012} & \multicolumn{3}{|c|}{2011} & \multicolumn{3}{|c|}{2010} & \multirow[t]{2}{*}{$T_{x}$} \\
\hline & $\mathbf{H}$ & $\mathbf{M}$ & $\mathbf{T}$ & $\mathbf{H}$ & $\mathbf{M}$ & $\mathrm{T}$ & $\mathbf{H}$ & $\mathbf{M}$ & $T$ & $\mathbf{H}$ & $\mathbf{M}$ & $T$ & \\
\hline BH & 14,2 & 25,6 & 17,5 & 9,3 & 11,3 & 9,9 & 9,0 & 9,4 & 9,1 & 16,7 & 13,6 & 15,7 & 3,5 \\
\hline BSB & 14,4 & 17,6 & 15,2 & 3,0 & 7,1 & 4,2 & 4,4 & 13,0 & 6,2 & 8,6 & 28,6 & 13,9 & 3,0 \\
\hline POA & 4,8 & 24,1 & 9,8 & 10,3 & 23,5 & 12,9 & 7,7 & 24,1 & 12,8 & 12,5 & 21,7 & 14,6 & 1,5 \\
\hline $\mathrm{RJ}$ & 6,1 & 14,8 & 9,1 & 0,7 & 6,1 & 2,4 & 3,9 & 13,5 & 6,9 & 18,2 & 38,4 & 20,1 & 0,8 \\
\hline RJ $^{89}$ & 30,3 & 34,5 & 31,8 & 25,0 & 35,4 & 28,6 & 19,5 & 29,7 & 20,7 & 22,3 & 40,4 & 28,4 & 1,4 \\
\hline SP & 14,7 & 21,8 & 16,7 & 10,6 & 22,9 & 14,1 & 12,5 & 26,8 & 16,1 & 13,0 & 22,1 & 15,3 & 1,3 \\
\hline
\end{tabular}

Fonte: SIM/SVS/MS; Emporis ${ }^{88}{ }_{-}^{89}{ }_{-}{ }^{90}$.

84 ROBERTS, D. et al. Influence of pesticide regulation on acute poisoning deaths in Sri Lanka. Bulletin of the World Health Organization, v. 81, n. 11, p. 789-798, 2003. p. 795; GUNNEL, D. et al. The impact of pesticide regulations on suicide in Sri Lanka. International Journal of Epidemiology, v. 36, p. 1235-1242, 2007. p. 1240.

85 DAMAS, F. et al. Tentativas de suicídio com agentes tóxicos: análise estatística dos dados do CIT/SC (1994 a 2006). Revista Brasileira de Toxicologia, v. 22, n. 1-2, p. 21-26, 2009. p. 24; FERREIRA, M.; FIGUEIREDO, M. Epidemiologia das intoxicações humanas por raticidas no Brasil. Revista Eletrônica Gestão \& Saúde, v. 4, n. 3, p. 861-870, 2013. p. 863; PIRES, M. C. Indicadores de risco para tentativa de suicídio por envenenamento: um estudo de caso-controle. 2014. 145 f. Tese (Doutorado) - Programa de Pós-Graduação em Neuropsiquiatria e Ciências do Comportamento, Universidade Federal de Pernambuco, Recife, 2014. p. 96; MARTINS, B. et al. Intoxicação por raticida em um Centro de Assistência Toxicológica. Revista da Rede de Enfermagem do Nordeste, v. 17, n. 1, p. 3-9, jan./ fev. 2016. p. 3.

86 GUNNEL, D.; NOWERS, M. Suicide by jumping. Acta Psychiatrica Scandinavica, v. 96, p. 1-6, 1997. p. 1-2.

87 WU, K.; CHEN, Y.; YIP, P. Suicide methods in Asia: implications in suicide prevention. International Journal of Environmental Research and Public Health, v. 9, p. 1135-1158, 2012. p. 1145.

88 Disponível em: <http://www.emporis.com>. Acesso em: 14 mar. 2018.

89 BH: Belo Horizonte/MG; BSB: Brasília/DF; POA: Porto Alegre/RS; RJ: Rio de Janeiro/RJ; SP: São Paulo/SP.

90 Dados do Rio de Janeiro nos anos, da esquerda para a direita, 2009, 2008, 2007 e 2006. 
As cinco cidades, juntas, representaram $63,7 \%$ de todos os suicídios por JLE no país, com uma média de 155,67 suicídios por ano; e, ainda mais, esse método representa grandes índices na totalidade de suicídios nesses locais.

Com essa estratificação, fica ainda mais claro que este é um evento muito mais incidente dentre mulheres, representando grande parcela de eventos suicidas nos grandes centros brasileiros. Incluem em todos os anos analisados não apenas suicídios de seus residentes, mas também, com exceção de POA, significativamente mais "óbitos por ocorrência" do que "óbitos por residência", ou seja: pessoas residentes em outras cidades deslocam-se às capitais para a realização de suicídio.

A inserção de dados referentes à cidade do Rio de Janeiro demonstra uma possível sazonalidade a se estabelecer. Isto porque, no período anterior a 2006, as taxas eram similares àquelas de 2013 a 2010; entretanto, entre 2009 e 2006, percebem-se taxas altíssimas decorrentes não da diminuição de outros métodos, mas do aumento de casos de suicídio por JLE; nenhum evento específico no período foi identificado como vetor desse incremento, mas a observação no futuro pode fornecer novas propostas; em Brasília e em Belo Horizonte, é também possível perceber, mais sutis, indicativos de sazonalidade.

\subsubsection{Sazonalidade}

A sazonalidade dos eventos suicidas é um importante dado a se considerar, caracterizando-se pela ocorrência distribuída no tempo de forma desigual. Como demonstra o Gráfico 09, dezembro-janeiro é um período que se destaca pela quantidade de suicídios no Brasil; setembro-outubro e março também são meses com altas incidências. Entretanto, de mais concreto, o que se pode perceber é que o inverno é o período de menor incidência de suicídios.

Gráfico 8 - Ocorrência de suicídios por meses do ano no Brasil — 2011/2013.

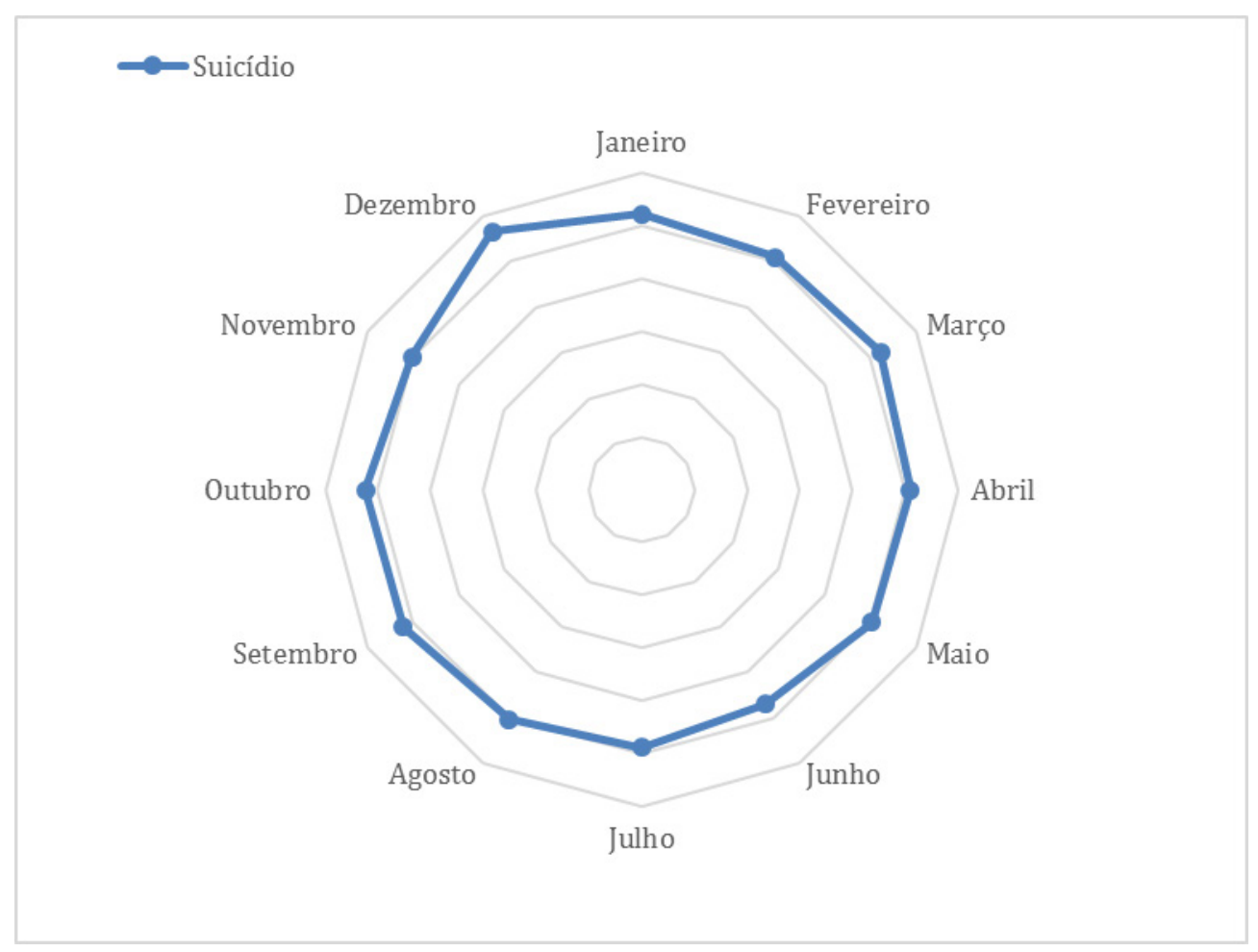

Fonte: SIM/SVS/MS. 
Diversos são os estudos que encontraram maiores índices de suicídios ou tentativas no verão ou na primavera, como estudos realizados em Portugal ${ }^{91}$; Finlândia ${ }^{92}$; Canadá $^{93}$; Bélgica ${ }^{94}$; Turquia ${ }^{95}$; e Lituânia, locais em em que se encontraram picos altíssimos no verão e grandes vazios no inverno ${ }^{96}$. Entretanto, também há estudo que não encontrou picos de suicídio na primavera ou verão ${ }^{97}$, ainda que tenha identificado correlação positiva entre ondas de calor e suicídios, como também encontraram Kovats e Ebi ${ }^{98}$ e Maes ${ }^{99}$.

Ademais, a sazonalidade pode ser ainda melhor demonstrada na análise das ocorrências ao longo da semana. Muitos são os estudos que concluíram haver picos às segundas-feiras e quedas bruscas em finais de semana, em especial no sábado, nos mais variados países, como Hungria ${ }^{100}$; Reino Unido ${ }^{101}$; Lituânia ${ }^{102}$; Suécia ${ }^{103}$ : Japão, em Hokkaido ${ }^{104}$; Eslovênia ${ }^{105}$; Estados Unidos, em Havaí ${ }^{106}$; Austrália ${ }^{107}$ : Estados Unidos, em Califórnia ${ }^{108}$; e Alemanha ${ }^{109}$. Fenômeno similar tem sido registrado em feriados. E alguns concluíram, em síntese, que, em dias anteriores a feriados, as taxas de suicídio caem, consideravelmente, e continuam baixas no dia do feriado, com incrementos sucessivos nos dias seguintes ${ }^{110}$.

91 FREITAS, E. O suicídio em Portugal no Século XX: elementos empíricos para uma pesquisa. Finisterra, Lisboa, v. 18, n. 34, p. 267-300, 1982. p. 282-283.

92 HERNETKOSKI, M.; KESKINEN, E.; PAKKARI, I. Driver suicides in Finland: are they different in northern and Southern Finland? International Journal of Circumpolar Health, v. 68, n. 3, p. 249-260, 2009. p. 257.

93 KIM, C. et al. Seasonal differences in psychopathology of male suicide completers. Comprehensive Psychiatry, v. 45, n. 5, p. 333339, sep./oct. 2004.

94 MAES, M. et al. Seasonal variation in Plasma L-Tryptophan availability in healthy volunteers' relationship to violent suicide occurrence. Arcbives of General Psychiatry, v. 52, p. 937-946, nov. 1995.

95 DOGANAY, Z. et al. Climatic and diurnal variation in suicide attempts in the ED. American Journal of Emergency Medicine, v. 21, n. 4, p. 271-275, july 2003.

96 KELEDIENE, R.; STARKUVIENE, S.; PETRAUSKIENE, J. Seasonal patterns of suicide over the period of socio-economic transition in Lithuania. BMC Public Health, v. 6, n. 40, feb. 2006. Disponível em: < http://www.ncbi.nlm.nih.gov/pmc/articles/PMC1397811>. Acesso em: 14 mar. 2018.

97 PAGE, L.; HAJAT, S.; KOVATS, S. Relationship between daily suicide counts and temperature in England and Wales. British Journal of Psychiatry, v. 191, p. 106-112, aug. 2007.

98 KOVATS, R.; EBI, K. Heatwaves and public health in Europe. European Journal of Public Health, v. 16, n. 6, p. 592-599, 2006.

99 MAES, M. et al. Synchronized annual rhythms in violent suicide rate, ambient temperature and the light-dark span. Acta Psychiatrica Scandinavica, v. 90, p. 391-396, 1994.

100 ZONDA, T. et al. The impact of holidays on suicide in Hungary. Omega, v. 58, n. 2, p. 153-162, 2008/2009.

101 PAGE, L.; HAJAT, S.; KOVATS, S. Relationship between daily suicide counts and temperature in England and Wales. British Journal of Psychiatry, v. 191, p. 106-112, aug. 2007.

102 KALEDIENE, R.; PETRAUSKIENE, J. Inequalities in daily variations of deaths from suicide in Lithuania: identification of possible risk factors. Suicide and Life-Threatening Behavior, v. 34, n. 2, p. 138-146, summer 2004.

103 BRÅDVIK, L.; BERGLUND, M. A suicide peak after weekends and holidays in patients with alcohol dependence. Suicide and Life-Threatening, v. 33, n. 2, p. 186-191, summer 2003.

104 NISHI, M. et al. Relationship between suicide and holidays. Journal of Epidemiology, v. 10, n. 5, p. 317-320, sep. 2000.

105 MARUŠIČ, A. Suicide in Slovenia: lessons for cross-cultural psychiatry. International Review of Psychiatry, v. 11, p. 212-218, 1999.

106 NAKAMURA, J. et al. Temporal variation in adolescent suicide attempts. Suicide and Life-Threatening Behavior, v. 24, n. 4, p. 343-349, 1994.

107 HASSAN, R. Temporal variation in suicide occurrence in Australia: a research note. The Australian \& New Zealand Journal of Statistics, v. 30, n. 2, p. 194-202, aug. 1994.

108 PHILLIPS, D.; SANZONE, A. A comparison of injury date and death date in 42,698 suicides. American Journal of Public Health, v. 78, n. 5, p. 541-543, may 1988.

109 MASSING, W.; ANGERMEYER, M. The monthly and weekly distribution of suicide. Social Science \& Medicine, v. 21, n. 4, p. 433-441, 1985.

110 PHILLIPS, D.; SANZONE, A. A comparison of injury date and death date in 42,698 suicides. American Journal of Public Health, v. 78, n. 5, p. 541-543, may 1988. p. 542; JESSEN, G.; JENSEN, B. Postponed suicide death? Suicides around birthdays and major public holidays. Suicide and Life-Threatening Behavior, v. 29, n. 3, p. 272-283, fall 1999. p. 277; BRÅDVIK, L.; BERGLUND, M. A suicide peak after weekends and holidays in patients with alcohol dependence. Suicide and Life-Threatening, v. 33, n. 2, p. 186-191, summer 2003. p. 189; KALEDIENE, R.; PETRAUSKIENE, J. Inequalities in daily variations of deaths from suicide in Lithuania: identification of possible risk factors. Suicide and Life-Threatening Behavior, v. 34, n. 2, p. 138-146, summer 2004. p. 140; PAGE, L.; HAJAT, S.; KOVATS, S. Relationship between daily suicide counts and temperature in England and Wales. British Journal of Psychiatry, v. 191, p. 106-112, aug. 2007. p. 107; ZONDA, T. et al. The impact of holidays on suicide in Hungary. Omega, v. 58, n. 2, p. 153-162, 2008/2009. p. 159. 
Ainda que com os dados fornecidos pelo SIM não seja possível verificar se essas sazonalidades ocorrem no Brasil, é razoável presumir, para a elaboração de políticas públicas, sua ocorrência, considerando a notória incidência ao redor de todo o mundo.

Com isto, tendo conhecido o fenômeno do suicídio e como ele se apresenta, é possível discutir o atual tratamento dado por governos à questão, bem como apresentar um caminho alternativo.

\section{Medidas de Combate ao SUICídIo}

\subsection{Suicídio como objeto de criminalização}

A partir da compreensão das diversas facetas desse fenômeno, é possível constatar sem embaraço que se trata de um sério e antigo problema pelo mundo.

Em reação, diversas têm sido as políticas públicas direcionadas ao controle desse fenômeno, em especial nas últimas décadas, com a progressiva mudança de entendimento acerca de sua natureza, sendo hoje visto essencialmente como uma questão de saúde pública; por isto, modelos criminalizantes têm sido progressivamente substituídos por modelos de promoção da saúde física e psicológica. Não é à toa que a produção científica acerca do suicídio está quase restrita à área de saúde, com finalidade absoluta de prevenção e cura de um comportamento tipicamente patológico.

Nos dias atuais, são poucos os países a manterem estatutos criminalizantes ${ }^{111}$ quanto a (tentativa de) suicídio, porém enquanto em alguns deles essa legislação raramente tem produzido efeitos, como Nigéria ${ }^{112}$, Líbano e Singapura ${ }^{113}$; há países em que ainda se visa a manter um rígido controle policial dos atos suicidas, como em Gana ${ }^{114}$ e Paquistão ${ }^{115}$.

Porém, com as ressalvas acerca das intenções manifestas e reais acerca de políticas de Estado, não é estranho entender medidas criminalizantes da tentativa de suicídio como não paternalistas. Afinal, inúmeras outras questões e argumentos estão em jogo, como a evitação de custos desnecessários com saúde pública ${ }^{116}$ ou mesmo a concepção de que a vida é sagrada, não pertencente ao indivíduo, mas a uma divindade, como na concepção islâmica ${ }^{117}$. Isto não afasta a possibilidade de que também seja encontrada a percepção — paternalista — de que a criminalização é capaz de proteger o indivíduo, evitando a tentativa e a reincidência ${ }^{118}$.

Pode surpreender, mas a criminalização recente do suicídio não se limita apenas a países asiáticos e africanos. Até 1955, ainda se aplicava na Inglaterra pena para criminosos cujo delito era a tentativa de suicídio ${ }^{119}$,

111 Ressalta-se que texto específico sobre modelos de criminalização do suicídio será publicado pelos autores no futuro próximo.

112 ADINKRAH, M. Anti-suicide laws in nine african countries: criminalization, prosecution and penalization. African Journal of Criminology and Justice Studies, v. 9, n. 1, p. 279-292, may 2016.

113 MISHARA, B.; WESSTUB, D. The legal status of suicide: a global review. International Journal of Law and Psychiatry, v. 44, p. 54-74, jan./feb. 2016.

114 ADINKRAH, M. Criminal prosecution of suicide attempt survivors in Ghana. International Journal of Offender Therapy and Comparative Criminology, v. 57, n. 12, p. 1477-1497, 2012.

115 SAREEN, H.; TRIVEDI, J. Legal implications of suicide problems specific to South Asia. Delhi Psychiatry Journal, v. 12, n. 1, p. 121-125, apr. 2009.

116 SAREEN, H.; TRIVEDI, J. Legal implications of suicide problems specific to South Asia. Delhi Psychiatry Journal, v. 12, n. 1, p. 121-125, apr. 2009.

117 ARAMESH, K.; SHADI, H. Euthanasia: an Islamic ethical perspective. Iranian Journal of Allergy, Asthma and Immunology, v. 6, n. 5 , p. 35-38, feb. 2007. p. 37.

118 OSAFO, J. et al. "We now have a patient and not a criminal": an exploratory study of judges and lawyers' views on suicide attempters and the law in Ghana. International Journal of Offender Therapy and Comparative Criminology [online], p. 1-21, jan. 2017. Disponível em: <http://journals.sagepub.com/doi/abs/10.1177/0306624X17692059>. Acesso em: 13 mar. 2018.

119 MENDELSON, D.; FRECKELTON, I. The interface of the civil and criminal law of suicide at common law (1194-1845). 
cuja descriminalização formal veio a ocorrer apenas com o The Suicide Act 1961; na Nova Zelândia, em 1961 ${ }^{120}$; no Canadá, em 1972 ${ }^{121}$; na Irlanda, em 1993 ${ }^{122}$; e, mesmo que realizada anteriormente, — mas surpreendente por conta da tradição liberal norte-americana - estados como Nova Iorque, Dakota do Sul e Dakota do Norte, no início do século $\mathrm{XX}^{123}$.

Ainda, não há como obliterar o delito de breach of the peace da tradição de common law (frisa-se que em Inglaterra e Canadá não possui status de delito, mas enseja detenção $\left.{ }^{124}\right)$. Destaca-se a jurisprudência escocesa, que se orienta no sentido de que esse delito ocorre quando uma ação é capaz de promover, ainda que não gere concretamente, distúrbio no homem-médio e ameaça a paz social ${ }^{125}$. Segundo esses postulados, considerou-se delito uma tentativa de suicídio em Torbet v. H. M. Advocate, (1998), S.C.C.R. 546, verificando-se uma carta branca para a incriminação também de atos suicidas.

É importante constatar ainda que a criminalização pode, não o sendo necessariamente, também ser instrumento essencialmente paternalista, seja aquela voltada diretamente ao suicida, casos raros atualmente; seja por meio da criminalização de ações auxiliares ou preparatórias de terceiros, extensamente encontrado por todos os continentes.

Em específico no Brasil, encontra-se no artigo 122 do Código Penal o delito de participação em suicídio, cujos elementos centrais compõem o auxílio, moral (sugestão, promoção psicológica) ou material (promoção de métodos), de modo que aquele que de alguma forma ajuda na realização do suicídio de um terceiro pode ser criminalizado, com pena entre dois e doze anos de reclusão. Ao se interpretar o dispositivo conforme a Constituição Federal de 1988, não há solução diversa de entendê-lo com natureza paternalista; porém na origem não era esse o objetivo, ao menos declarado. Constituído à época do Estado Novo, o Código Penal brasileiro não tinha como foco o indivíduo, a promoção de seu bem-estar, mas sim a consecução de uma política coletivista, organicista ${ }^{126}$, de modo que se entende como um bom exemplo da possibilidade de transformação da natureza (paternalista ou não) de determinadas medidas ao longo do tempo.

Enfim, é possível afirmar que esse estatuto brasileiro possui um grau de intermediário rigor quanto à participação em suicídio, pois há países em que a pena para esse delito é prisão perpétua, em especial afri$\operatorname{canos}^{127}$, bem como países que têm progressivamente promovido o suicídio assistido, como por exemplo Suíça ${ }^{128}$ e Bélgica ${ }^{129}$. Notório é o caso suíço, em que a prática é permitida e significativamente regulamentada, sendo exigido que o suicida seja considerado plenamente capaz por um médico, que receitará a droga letal, que será manipulada pelo suicida em parceria com um voluntário de uma ONG credenciada. Essa possibilidade decorre da lacuna existente no Código Penal suíço, que prevê em seu artigo 115 a tipificação da participação em suicídio apenas em casos com motivação egoísta, bem como pela vitória da concepção do

International Journal of Law and Psychiatry, v. 36, n. 5-6, p. 343-349, 2013.

120 LESTER, D. Decriminalization of suicide in New Zealand and suicide rates. Psychological Reports, v. 72, n. 3, p. 1050 , june 1993.

121 LEENAARS, A.; LESTER, D. Comparison of rates and patterns of suicide in Canada and the United States, 1960-1988.

Death Studies, v. 16, n. 5, p. 417-430, 1992. p. 427.

122 NEELEMAN, J. Suicide as a crime in the UK: legal history, international comparisons and present implications. Acta Psychiatrica Scandinavica, v. 94, n. 4, p. 252-257.

123 WITHERS, R. Status of suicide as a crime. The Virginia Law Register, v. 19, n. 9, p. 641-647, jan. 1914. p. 642.

124 FERGUSON, P. Moving from preparation to perpetration? Attempted crimes and breach of the peace in scots law. Obio State Journal of Criminal Law, v. 11, n. 2, p. 687-700, 2014.

125 Smith v. Donnelly, 2002, JC 65; reafirmado na Corte Europeia de Direitos Humanos: Maguire v. Reino Unido, 28 , p. 7.

126 CAMPOS, F. Síntese da reorganização Nacional (entrevista concedida à imprensa, em abril de 1939). In: CAMPOS, F. $O$

Estado Nacional: sua estrutura, seu conteúdo ideológico. Brasília: Senado Federal, 2001. p. 107-136. p. 124-125.

127 ADINKRAH, M. Anti-suicide laws in nine african countries: criminalization, prosecution and penalization. African Journal of Criminology and Justice Studies: v. 9, n. 1, p. 279-292, may 2016.

128 ADORNO, R. Nonphysician-assisted suicide in Switzerland. Cambridge Quarterly of Healthcare Ethics, v. 22, n. 3, p. 246-253, july 2013; STECK, N. et al. Euthanasia and assisted suicide in selected European countries and US States: systematic literature review. Med Care, v. 51, n. 10, p. 938-944, oct. 2013.

129 ZIEGLER, S.; BOSSHARD, G. Role of non-governmental organisations in physician assisted suicide. BMJ, v. 334, p. 295298, feb. 2007. 
direito de morrer, evidenciado na não adesão do entendimento de que essa lacuna poderia ser preenchida com a tipificação da ação do voluntário ou do médico como homicídio ou omissão de socorro ${ }^{130}{ }^{131}$.

Essa regulamentação suíça da participação em suicídio é o mais forte vetor que se tem hoje no sentido da referida descriminalização do suicídio, acompanhando e promovendo essa tendência, entretanto, não exclui a visão patológica, que orienta o tratamento e cura de indivíduos não plenamente capazes, ou seja, não elegíveis para o suicídio assistido.

De qualquer forma, essa polarização (medidas criminalizantes versus atenção médica) evidencia duas formas muito diversas de lidar com o suicídio. Isto porque a criminalização do ato suicida tem por base um agente livre, capaz, consciente; enquanto a criminalização de atos acessórios de terceiros e a medicalização denotam um indivíduo incapaz, doente, desorientado por uma deficiência ou desordem psíquica, ou seja, como se apresentou, o típico destinatário de medidas paternalistas, afinal não é capaz de dirigir-se conforme seu próprio bem-estar.

Por fim, nota-se que opção por modelos criminalizantes parece estar atrelada diretamente a concepções antigas da relação entre Poder Central, vinculadas ou não a sentimentos religiosos, e indivíduos, não guardando qualquer relação concreta com estudos de viabilidade ou efetividade. Nessa seara, apenas se encontram, em específico quanto à tentativa de suicídio, estudos indicando a absoluta incapacidade de políticas repressivas prevenirem sua realização e a ausência de incremento de eventos suicidas a partir de descriminalizações, como detectado, por exemplo, em Sri Lanka ${ }^{132}$, Inglaterra ${ }^{133}$ e Irlanda ${ }^{134}$.

Com isto, modelos criminalizantes se mostram, além de naturalmente custosos, improdutivos se aplicados a um tema de saúde pública como o suicídio, possivelmente gerando inúmeros outros problemas de saúde pública e até mesmo institucionais. Por exemplo, a difusão da corrupção de autoridades policiais paquistaneses responsáveis por hospitais médico-legais a que são obrigatoriamente levados os sobreviventes, com o fim de se evitar as acusações por tentativa de suicídio ${ }^{135}$.

Não é à toa que têm ganhado cada vez mais espaço medidas interventivas de caráter não criminalizantes, políticas públicas de contenção e restrição a disponibilidade de métodos suicidas, como se expõe a seguir.

\subsection{Suicídio como objeto de políticas públicas não criminalizantes}

Como já exposto, é notório que a disponibilidade do método é elemento central na escolha do suicida para realização de seu intento ${ }^{136}$. Com base nisso, têm-se promovido inúmeras medidas interventivas com a finalidade de dificultar ou até mesmo impossibilitar o acesso de indivíduos a meios de suicídio. Também medidas educativas vêm sendo implementadas, sejam em âmbito de atendimento médico, sejam voltadas diretamente a público geral ou de alto risco. Em síntese, é possível afirmar de antemão que se tem promovido a concepção de complementariedade dessas medidas de controle, restrição, informações e educação.

Quanto a medidas restritivas, podem ser citadas como expoentes aquelas relacionadas ao acesso a armas de fogo, o controle e restrição ao tráfego de pessoas em estações e trilhos de sistemas ferro e metroviários, bem como em pontes.

130 HURST, S.; MAURON, A. Assisted suicide in Switzerland: clarifying liberties and claims. Bioethics, v. 31, n. 3, p. $199-208$, mar. 2017.

131 Ressalta-se novamente, que em texto a ser publicado os autores abordarão mais detalhadamente o tema.

132 HOEK, W. et al. Pesticide poisoning: a major health problem in Sri Lanka. Social Science \& Medicine, v. 46, n. 4-5, p. 495-504, feb. 1998.

133 BULlUSU, L.; ALDERSON, M. Suicides 1950-82. Population Trends, v. 35, p 11-17, spring 1984.

134 OSMAN, M.; PARNELL, A.; HALEY, C. "Suicide shall cease to be a crime": suicide and undetermined death trends 19702000 before and after the decriminalization of suicide in Ireland 1993. Irish Journal of Medical Science, v. 186, n. 1, p. 201-205, feb. 2017.

135 KHAN, M. et al. Epidemiology of suicide in Pakistan: determining rates in six cities. Archives of Suicide Research, v. 12, n 2, p. 155-160, 2008.

136 BETZ, M. et al. Lethal means access and assessment among suicidal emergency department patients. Depression and Anxiety, v. 33, n. 6, p. 502-511, june 2016. 


\subsubsection{Controle de armas de fogo}

Em específico quanto a armas de fogo, cujo altíssimo grau de letalidade já foi relatado, visa-se a restringir ao máximo a disponibilidade de armas, seja a todos os indivíduos, seja a grupos de riscos. O debate acerca da disponibilidade de armas de fogo é notoriamente tortuoso, evidenciando o mencionado problema da liberdade individual frente ao paternalismo.

Essa dicotomia se mostra mais evidente nos Estados Unidos, onde há um fortíssimo embate. Portanto, naturalmente, em que pesem inúmeros estudos demonstrarem a direta relação entre posse de arma de fogo e maior risco de evento suicida por arma de fogo ${ }^{137}$, também se encontram aqueles que, em oposição, defendem a utilização de arma de fogo como instrumento essencial e eficaz de defesa contra a criminalidade ${ }^{138}$, a ponto de a National Rifle Association (NRA) ter iniciado um estudo de viabilidade de instalar seguranças armados em escolas após o massacre em Sandy Hook Elementary School, em 2012, sob seu famigerado mantra de que "apenas um bom homem com uma arma é capaz de impedir um homem mau com uma arma"139.

Diversas podem ser as medidas restritivas, mas não impeditivas, do uso de armas de fogo, a saber: a) quanto ao comércio: i) limitação de produção; ii) limitação de importação; iii) banimento de carregadores com grande capacidade; iv) banimento de armas conhecidas como saturday night special, ou seja, pistolas de baixa qualidade e segurança, às vezes de reduzidíssimo tamanho e difícil fiscalização; v) sobretaxação; b) quanto à aquisição: i) idade mínima para aquisição: ii) teste psicológico; iii) conferência de antecedentes criminais; iv) exigência de motivação justificada para aquisição; v) realização de curso de manuseio; vi) cooling off period, ou seja, tempo de espera para efetivação da compra após solicitação; vii) licenciamento ou registro dos comerciantes; viii) registro dos compradores; c) quanto ao uso: i) licença restrita: utilização somente em situações justificadas perante autoridades; ii) especificações quanto à forma de armazenamento, inclusive de munições; iii) utilização de travas de segurança.

Bons resultados foram obtidos em Columbia, que adotou em 1976 um dos mais restritivos programas de controle de armas dos Estados Unidos por meio do Distric of Columbia's Firearms Control Regulations Act, exigindo o registro de armas, seu armazenamento sem munição, desmontadas e com trava de segurança, tendo sido registrada uma grande redução nos índices de suicídio e homicídio, sem a verificação de displacement ${ }^{40}$; em específico quanto aos efeitos de travas de segurança, também obtiveram sucesso os estados de Tennessee e Washington ${ }^{141}$.

Outros dados relevantes são encontrados em um estudo que não identificou redução dos índices de suicídios, bem como de homicídios, dentre jovens, nos estados que limitaram o acesso a armas de fogo a maiores de 21 anos; porém detectou redução de 8\% das taxas de suicídio por arma de fogo nos estados que vedaram as saturday night specials ${ }^{142}$.

137 WINTEMUTE, G. et al. Mortality among recente purchasers of handguns. The New England Journal of Medicine, v. 341, n. 21, p. 1583-1589, 1999; CONNER, K.; ZHONG, Y. State firearm laws and rates of suicide in men and women. American Journal of Preventive Medicine, v. 25, n. 4, p. 320-324, 2003; DAHLBERG, L.; IKEDA, R.; KRESNOW, M. Guns in the home and risk of a violent death in the home: findings from a national study. American Journal of Epidemiology, v. 160, n. 10, p. 929-936, nov. 2004; MILLER, M. et al. The association between changes in household firearm ownership and rates of suicide in the United States, 1981-2002. Injury Prevention, v. 12, n. 3, p. 178-182, june 2006.

138 BRUCE-BRIGGS, B. The great American gun war. The Public Interest, n. 45, p. 37-62, 1976; KLECK, G.; GERTZ, M. Armed resistance to crime: the prevalence and nature of self-defense with a gun. Journal of Criminal Law and Criminology, v. 86, n. 1, p. 150187, fall 1995 .

139 STEIDLEY, T.; COLEN, C. Framing the gun control debate: press releases and framing strategies on the National Rifle Association and the Brady Campaign. Social Science Quarterly, v. 98, n. 2, p. 608-627, june 2017. p. 608.

140 LOFTIN, C. et al. Effects of restrictive licensing of handguns on homicide and suicide in the District of Columbia. The New England Journal of Medicine, v. 325, n. 23, p. 1615-1620, dec. 1991.

141 KELLERMAN, A. L. et al. Suicide in the home in relation to gun ownership. The New England Journal of Medicine, v. $327, \mathrm{p}$. 467-472, aug. 1992.

142 ROSENGART, M. et al. An evaluation of state firearm regulations and homicide and suicide death rates. Injury Prevention, v. 11, n. 2, p. 77-83, apr. 2005. 
Outro bom exemplo a respeito dos efeitos da disponibilidade das armas de fogo é o caso da Suíça, que, tradicionalmente, tem como principal método de suicídio o uso de arma de fogo ${ }^{143}$; e cujos índices de homicídios por arma de fogo estão diretamente relacionados ao número de possuidores ${ }^{144}$. No país, sempre houve uma grande disponibilidade de armas em função do programa militar, que até 2010 mantinha as armas de fogo sob a posse de todos os indivíduos egressos do programa obrigatório ${ }^{145}$; e, desde a referida data, apenas aqueles que obtêm uma licença especial podem detê-las. A própria redução do efetivo do exército, ocorrida em 2003, foi uma medida, ainda que sem esse propósito, eficiente na redução dos índices de suicídio com base na redução geral de disponibilidade de $\operatorname{armas}^{146}$.

Em síntese, é possível afirmar, categoricamente, que, quanto mais armas de fogo disponíveis e/ou maior liberdade em sua forma de uso, maiores os índices de suicídios por arma de fogo e, por consequência, de suicídios em geral, considerando a altíssima letalidade desse método. Também é indiscutível a existência de elevados custos econômicos e políticos na promoção de medidas restritivas nesse campo.

\subsubsection{Limitações à livre-circulação de pessoas em hotspots}

Ainda que boa parte dos atos suicidas ocorram no silêncio e intimidade de residência privadas, é bastante significativo o número de eventos em locais públicos, havendo pesquisas que indicam mais de $30 \%$ dos casos ocorrendo nesses locais ${ }^{147}$. Falando quanto a espaço público, é notória a existência de hotspots, ou seja, aqueles em que uma mística e o histórico promovem a repetição contínua de eventos suicidas, atraindo pessoas e elevando as estatísticas locais; estes podem ser shoppings, pontes, prédios comerciais, universidades, estações de trens etc.

Considerando isto, as características desses lugares, bem como a dinâmica dos eventos suicidas têm sido estudados meios de impedir, fisicamente, o acesso de potenciais suicidas aos pontos críticos desses hotspots. Consequentemente, estudos têm vindo à tona discutindo a efetividade e custo-benefício dessas medidas, seja de forma geral ou específica, com destaque para o estudo de Pirkis e Spittal, que, em uma meta análise, concluíram pela grande eficiência de barreiras de segurança em hotspots ${ }^{148}$. Um bom exemplo desse tipo de local é a ponte Golden Gate, em São Francisco (EUA), que, entre 1937 e 1991, registrou 918 casos, uma média de 19,5 casos por ano ${ }^{149}$, sendo previsto um plano de contenção de suicídios por meio da instalação de redes de segurança de aço inoxidável ao longo de toda sua extensão, que se prevê conclusa em janeiro de 2021, porém ao custo de $\$ 204.000 .000$,00. Entretanto, já se aponta a inexistência de prejuízo econômico — se é que se pode abordar a questão dessa forma — pela economia com despesas decorrentes de eventos (tentados ou consumados) suicidas evitados ${ }^{150}$.

Em específico quanto a evitação de suicídios em pontes, são inúmeros os casos de sucesso por meio

143 VÄRNIK, A. et al. Suicide methods in Europe: a gender-specific analysis of countries participating in the "European Alliance Against Depression". Journal of Epidemiology and Community Health, v. 62, p. 545-551, 2008.

144 AJDACIC-GROSS, V. et al. Firearm suicides and availability of firearms: the swiss experience. European Psychiatry, v. 25, p. 432-434, 2010.

145 HABENSTEIN, A. et al. Chances and limits of method restriction: a detailed analysis of suicide methods in Switzerland. Archives of Suicide Research, v. 17, n. 1, p. 75-87, 2013.

146 REISCH, T. et al. Change in suicides rates in Switzerland before and after firearm restriction resulting from the 2003 "Army XXI" reform. The American Journal of Psychiatry, v. 170, n. 9, p. 977-984, sep. 2013.

147 OWENS, C. et al. Suicide in public places: findings from one English county. European Journal of Public Health, v. 19, n. 6, p. 580-582, apr. 2009; CHEN, Y.; YIP, P. Prevention of suicide by jumping: experiences from Taipei City (Taiwan), Hong Kong and Singapure. In: WASSERMAN, D.; WASSERMAN, C. Oxford Textbook of Suicidology and Suicide Prevention. Oxford: Oxford University Press, 2009. p. 569-572.

148 PIRKIS, J.; SPITTAL, M. The effectiveness of structural interventions at suicide hotspots: a meta-analysis. International Journal of Epidemiology, v. 42, p. 531-548, 2013.

149 GUNNEL, D.; NOWERS, M. Suicide by jumping. Acta Psychiatrica Scandinavica, v. 96, p. 1-6, 1997.

150 WHITMER, D.; WOODS, D. Analysis of the cost effectiveness of a suicide barrier on the Golden Gate Bridge. Crisis, v. 24, n. 2, p. 98-106, 2013. 
da instalação de cercas, redes e outras barreiras. Um amplo estudo suíço quanto a efetividade identificou redução de $82 \%$ de suicídios em hotspots em função de barreiras (barreiras verticais e redes de segurança) completas, ou seja, em torno de todo o perímetro de risco; enquanto identificou redução de 44,8\% em hotspots com barreiras incompletas; ou seja, ainda que se mantenha alguma disponibilidade, possivelmente há um forte impacto psicológico nos potenciais suicidas ${ }^{151}$. Situação similar foi identificada no Münsterplattform, em Berna, cujo impacto se estendeu a toda a cidade, reduzindo os índices desse método drasticamente não apenas nesse botspot ${ }^{152}$.

Ainda, há os casos da Clifton Suspension Bridge, em Bristol, em que o número de suicídios foi reduzido pela metade nos anos seguintes à instalação de barreiras ${ }^{153}$; bem como do Prince Edward Viaduct, em Toronto, onde foi instalado gradeado elevado de cerca de $5 \mathrm{~m}$, o que não impossibilitou a ocorrência de um suicídio, mas, além de reduzir drasticamente os índices no local, aparentemente também ensejou redução de suicídios por esse método em toda a cidade ${ }^{154}$, como se a construção das barreiras tivesse funcionado como uma mensagem com efeitos psicológicos da indesejabilidade daquela espécie de conduta. Entretanto, há também meios mais simples e menos onerosos, como impedir a circulação e travessia de pedestres, em que pese isto não impedir que as pessoas se dirijam até ponto elevado por meio de automóvel para, então, se precipitarem, como muito já ocorreu na Ponte do Bósforo, em Istambul ${ }^{155}$.

Menos custosa do que essas barreiras, a instalação de linhas telefônicas diretas, Helplines, em hotspots, como a MID-Hudson Bridge, no estado de Nova Iorque. Funcionando 24h por dia, o telefone de emergência foi utilizado, em apenas dois anos, por 24 indivíduos com ideação suicida. Apenas um deles, efetivamente, se precipitou da ponte; enquanto os demais foram recolhidos e colocados sob supervisão psiquiátrica ${ }^{156}$. Outro meio menos custoso seria a criação de protocolos de segurança específicos para a construção de novas edificações ${ }^{157}$.

Por fim, pode-se falar da instalação de portas especiais em estações de metrô e trem, que impedem o acesso aos trilhos e se abrem quando os veículos estacionam: as Portas de Plataformas, sejam elas integrais (Platform Screen Doors - PSDs) ou parciais, a meia altura (Platform Edge Doors - PED), encontradas, inclusive, em algumas estações de transporte metroferroviário de São Paulo. Exemplos de sucesso podem ser observados em Tóquio ${ }^{158}$, Hong Kong ${ }^{159}$ e Seul ${ }^{160}$. Entretanto, essas barreiras são significativamente caras, em especial as PSDs, exigindo altos custos não apenas de sua instalação e manutenção, mas também quanto à estrutura da estação.

Em virtude desse alto custo, encontrou-se no Japão uma alternativa de natureza diversa, sem qualquer restrição aos usuários do sistema de transporte: a instalação de luz azul nas estações, com fundamento de

151 HEMMER, A.; MEIER, P.; REISCH, T. Comparing different suicide prevention measures at bridges and buildings: lessons we have learned from a national survey in Switzerland. Plos One, v. 12, n. 1, jan. 2017.

152 REISCH, T.; MICHEL, K. Securing a suicide hot spot: effects of a safety net at the Bern Muenster Terrace. Suicide and LifeThreatening Behavior, v. 35, n. 4, p. 460-467, aug. 2005.

153 BENNEWITH, O.; NOWERS, M.; GUNNEL D. Effect of barriers on the Clifton suspension bridge. The British Journal of Psychiatry, v. 190, p. 266-267, mar. 2007.

154 SINYOR, M.; LEVITT, A. Effect of a barrier at Bloor Street Viaduct on suicide rates in Toronto: natural experiment. BMJ, v. 341, july 2010; SINYOR, M.; SCHAFFER, A.; REDELMEIER, D. et al. Did the suicide barrier work after all? Revisiting the Bloor Viaduct natural experiment and its impact on suicide rates in Toronto. BMJ Open, v. 7, n. 5, june 2017.

155 ÇETIN, G.; GÜNAY, Y.; FINCANCI, S. et al. Suicides by jumping from Bosphorus Bridge in Istanbul. Forensic Science International, v. 116, n. 2-3, p. 157-162, feb. 2001.

156 GLATT, K. Helpline: suicide prevention at a suicide site. Suicide Life-Threatening Behavior, v. 17, n. 4, p. 299-309, winter 1987.

157 PIRKIS, J.; SPITTAL, M. The effectiveness of structural interventions at suicide hotspots: a meta-analysis. International Journal of Epidemiology, v. 42, p. 531-548, 2013.

158 UEDA, M.; SAWADA, Y.; MATSUBAYASHI, T. The effectiveness of installing physical barriers for preventing railway suicides and accidents: evidence from Japan. Journal of Affective Disorders, v. 178, p. 1-4, 2015.

159 LAW, C. et al. Evaluating the effectiveness of barrier installation for preventing railway suicides in Hong Kong. Journal of Affective Disorders, v. 114, n. 1-3, p. 254-262, apr. 2009.

160 CHUNG, Y. et al. The effectiveness of platform screen doors for the prevention of subway suicides in South Korea. Journal of Affective Disorders, v. 194, p. 80-83, apr. 2016. 
que teria efeito, grosso modo, calmante nas pessoas e, portanto, poderia limitar em algum grau comportamentos impulsivo-agressivos, sejam suicídios ou mesmo lesões a terceiros. Similar expediente tem sido implementado lentamente no Reino Unido, entretanto, até o momento apenas um estudo se propôs a analisar os efeitos dessa medida, concluindo pela existência de um grande declínio de suicídios nas estações em que foi implementada, ainda que não haja como fazer correlações absolutas ${ }^{161}$. Portanto, as cidades e suas estruturas podem e devem ser utilizadas tanto como instrumentos de promoção de direitos, como de sua garantia $^{162}$.

\subsection{Protonudging}

Como se observou, as políticas quanto ao suicídio atualmente são consoantes à dicotomia pertinente ao debate tradicional sobre paternalismo de Estado: de um lado, criminalização, proibições, chegando a restrições a consumo e construção de barreiras; de outro, campanhas educacionais, sensibilização de instituições públicas, abertura de linhas telefônicas de suporte etc. A despeito dessa divisão, pelo menos duas iniciativas atuais agregam características de ambos os lados, conformando-se como uma manifestação, ainda que não planejada por seus idealizadores, de paternalismo libertário.

Tendo em vista que a discussão acerca de nudging ainda está em um grau prematuro de penetrabilidade no campo das políticas públicas ${ }^{163}$, essas iniciativas, apesar da viabilidade, não foram enquadradas como nudges à época de sua formulação. Não obstante, esses exemplos podem servir de parâmetro para a elaboração de nudges direcionados ao combate ao suicídio.

O primeiro exemplo é a cartilha criada pela Associação Brasileira de Psiquiatria (ABP) com orientações sobre a abordagem de suicídio na imprensa, criada com base nas diretrizes do respectivo manual da Organização Mundial de Saúde. Manuais e cartilhas, a princípio, têm caráter exclusivamente informativo, afirmando diretrizes gerais, e, por essa razão, são enquadrados como manifestações do extremo liberal no debate tradicional sobre paternalismo de Estado. A cartilha em questão, contudo, vai além da mera exposição de diretrizes, transmitindo sugestões de pequenas e sutis alterações na forma como a informação é apresentada, de modo a direcionar comportamentos sem que opções sejam limitadas.

Nesse sentido, dentre o rol das dicas aos profissionais de imprensa ${ }^{164}$, alguns trechos podem ser destacados, como "evitar a palavra suicídio em chamadas e manchetes. Melhor incluí-la no corpo do texto; evitar termos valorativos, como por exemplo: 'cometeu' suicídio; tentou o suicídio 'sem sucesso'; ou generalizantes, como, por exemplo 'os suicidas', ao referir-se a pessoas falecidas por suicídio”; é “aconselhável não dar destaque à notícia: no caso de jornais, em páginas pares e na parte inferior. Em TV, do terceiro bloco em diante; o mesmo se aplica a programas de rádio. Esclarecer as consequências do ato em si, seja na forma de danos físicos e mentais permanentes (no caso de tentativa), seja no impacto que provoca na família e amigos"; "em alguns casos, é prudente omitir o local onde o ato foi realizado".

Não apenas medidas tidas como liberais podem se aproximar de um caminho intermediário, mas também uma medida comumente enquadrada como uma manifestação de paternalismo forte pode ser relativizada. Por exemplo a restrição a meios letais por meio do cooling off period em aquisição de armas e da intervenção na acessibilidade a carvão em Hong Kong.

161 MATSUBAYASHI, T.; SAWADA, Y.; UEDA, M. Does the installation of the blue lights on train platforms prevent suicide? A before-and-after observational study from Japan. Journal of Affective Disorders, v. 147, p. 385-388, 2013.

162 DIAS, D.; NONATO, D.; RAIOL, R. Interação entre a acessibilidade urbanística e o direito à cidade: possibilidade de inclusão social das pessoas com deficiência. Revista Brasileira de Políticas Públicas, v. 7, n. 2, p. 149-168, ago. 2017.

163 Políticas públicas baseadas em evidências comportamentais vêm ganhando espaço em governos pelo mundo, com destaque para a primeira iniciativa neste sentido, o BIT (Behavioral Insights Team), criado pelo então primeiro ministro David Cameron do Reino Unido em 2010; e o SBST (Social and Behavioral Sciences Team), criado em 2015 pelo ex-presidente dos Estados Unidos Barack Obama. 164 ASSOCIAÇÃO BRASILEIRA DE PSIQUIATRIA. Manual para a imprensa: boas práticas de comunicação e guia com recomendações para um texto claro e esclarecedor sobre doenças mentais e psiquiatria. 2. ed. Rio de Janeiro: ABO, 2009 . p. 85 e ss. 
Em específico quanto a esse último caso, trata-se de experimento levado a cabo entre julho de 2006 e junho de 2007 em dois distritos adjacentes em Hong Kong — Tuen Mun e Yuen Long — com características demográficas e socioeconômicas parecidas, além de altos índices de suicídios com o uso da técnica de queima de carvão ${ }^{165}$. Nos mercados de Tuen Mun (distrito que sofreu a manipulação), o carvão de churrasco deixou de ser ofertado em prateleiras para serem entregues aos consumidores exclusivamente após pedido a funcionários, que teriam que buscar o produto em área interna, processo que levaria, em média, 10 minutos. Os mercados de Yuen Long (distrito usado como controle para o experimento) continuaram vendendo carvão normalmente, ou seja, dispondo livremente em prateleiras.

Ao analisar o resultado da intervenção após um ano, os pesquisadores notaram que, no distrito de Tuen Mun, onde o acesso a carvão foi dificultado, o número de suicídios por esse método diminuiu consideravelmente, de 21 para 10 casos e o número total de suicídios também diminuiu de 88 para 60, o que indica ausência de displacement. A despeito das limitações deste estudo, há evidências de que pequenas alterações no ambiente podem gerar efeitos significativos de dissuasão do comportamento suicida.

Em comum, ambas iniciativas apresentam características típicas de nudges: trata-se de alterações sutis na arquitetura da decisão que não retiram opções das pessoas ${ }^{166}$; direcionam-se à mudança comportamental, não à mudança de opinião ou ao convencimento de seus destinatários ${ }^{167}$; baseiam-se em evidências, não em intuições de seus planejadores, tanto na fase de elaboração quanto na fase de avaliação de resultados ${ }^{168}$; são formuladas a partir de um mapeamento do contexto da decisão, isto é, tendo-se em conta o grau de atenção, as pressões sociais e as heurísticas utilizadas pelas pessoas para a tomada de decisão $0^{169}{ }_{-170}$.

\section{Considerações finais: Pelo desenVolvimento do mÉtodo de NUdGes para políticas PÚBLICAS DE COMBATE A SUICÍDIOS}

Com base nos elementos apresentados, os elementos apresentados: o critério para enquadramento de paternalismo (parte I); as evidências sobre as características e evolução do suicídio (parte II); a metodologia e exemplos de nudges (parte III); pergunta-se: afinal, por que incorporar nudges às políticas públicas no combate ao suicídio?

De acordo com Sunstein: “[a] virtude [dos nudges é] [...] desenvolver políticas sensíveis, e de baixo custo, com referência a como seres humanos realmente pensam e se comportam"171. Políticas públicas comportamentais (behavioral policies) em regra têm a virtude de serem uma alternativa de implementação imediata e simples, além de possuírem melhor custo-benefício em relação às opções tradicionais ${ }^{172}$. Esse menor custo

165 YIP, P. et al. Restricting the means of suicide by charcoal burning. The British Journal of Psychiatry, v. 196, p. 241-242, 2010.

166 THALER, R.; SUNSTEIN, C. Nudge: improving decisions about health, wealth and happiness. New Haven: Yale University Press, 2008. p. 5.

167 SAMSON, A. The behavioral economics guide 2016: with introduction by Gerd Gigerenzer. Londres: Behavioral Science Solutions, 2016. p. 31.

168 SUNSTEIN, C. Nudging: a very short guide. Journal of Consumer Policy, v. 37, n. 4, p. 583-588, dec. 2014.

169 LY, K. et al. A practitioner's guide to nudging. Research Report Series Behavioural Economics in Action, Rotman School of Management, University of Toronto, Toronto, p. 1-28, mar. 2013. p. 15.

170 A título de exemplo, apresentam-se categorias de intervenções mais recorrentes: (i) inscrições automáticas (default) (e.g. inscrição automática no plano de previdência privada mais benéfica, com opção de saída a qualquer momento) (THALER, R.; SUNSTEIN, C. Nudge: improving decisions about health, wealth and happiness. New Haven: Yale University Press, 2008. p. 103-117); (ii) utilização de normas sociais (e.g. dar ênfase ao fato de a maioria dos adultos de uma região estão registrados para doação de órgãos) (p. 182); e (iii) enquadramento (framing) de informações (e.g., reenquadrar a informação de forma a elicitar o viés da aversão à perda no destinatário, como alterar "mantenha-se hidratado" para "pare de perder água") (p. 244). Para uma discussão sobre situações em que se deve optar por nudges, em especial regras default, ou opções tradicionais que exijam escolha ativa por parte do destinatário, ver SUNSTEIN, C. Choosing not to choose: understanding the value of choice. New York: Oxford University Press, 2015.

171 SUNSTEIN, C. Why nudge?: the politics of libertarian paternalism. New Haven: Yale University Press, 2014. p. 25, tradução livre.

172 BENARTZI, S. et al. Should governments invest more in nudging?. Psychological Science, Thousand Oaks, june 2017. Dis- 
não seria apenas econômico (pequenas alterações na arquitetura da decisão em comparação a ampliação de campanhas educacionais ou gastos com mais controle, fiscalização e repressão), mas também político se comparado a medidas de paternalismo forte. Afinal, a defesa de nudges, em razão de seu traço não restritivo ou coercitivo, sofreria menos resistência das pessoas em razão da percepção de preservação de liberdade de escolha.

Portanto, é possível sugerir alguns nudges para o combate ao suicídio, primordialmente com a finalidade de promover o debate quanto à incorporação dessa metodologia às políticas públicas.

1. Considerando que histórico de tentativas é um grande fator de risco ${ }^{173}$, após o atendimento em emergência decorrente de uma tentativa de suicídio, o indivíduo será automaticamente inserido em um programa de atendimento psicológico (regra default) por telefone (helpline). Isto porque é notória, há muito tempo, a indisposição de pacientes a acompanhamento após alta médica $(\text { follow-up })^{174}$. O cancelamento da inscrição nesse programa apenas pode ser feito mediante manifestação que deverá ser entregue, presencialmente, pelo indivíduo no respectivo órgão público (possibilidade de opt-out). Dessa forma, baseado nas evidências de tendência das pessoas a se conformarem ao status quo ou inércia, acreditamos que grande parte das pessoas que podem se beneficiar de apoio psicológico acabariam por continuar recebendo atenção continuada, haja vista existir demonstração de menores índices de suicídios em grupos com intenso contato em follow-up ${ }^{175}$.

2. Em se considerando que há datas de picos de incidência em suicídios, como segundas-feiras ou dias posteriores a feriados e ao longo do verão, uma medida com potencial de eficácia é a sugestão/indicação a profissionais de imprensa para que optem, na medida do possível, por apresentar/retardar notícias com teor positivo, como melhoras em índices econômicos, em/para finais de semana e dias anteriores aos feriados.

3. É razoável considerar que grande parte das pessoas que estão na iminência de realizar suicídio estão passando por uma situação de "tunelamento atencional", isto é, alocando todos recursos cognitivos em linhas de pensamento circulares e repetitivos, deixando de considerar alternativas. Por essa razão, acreditamos que em hotspots, locais comumente de altitude elevada e com grande incidência de suicídios, como pontes, em vez, ou mesmo complementarmente, de se limitar a circulação ou criar barreiras físicas, pode ser razoável usar de meios para causar a interrupção do "túnel atencional" suicida por meios direcionados a engatilhar temporariamente o uso do sistema 2 de raciocínio (vide Quadro 1).

Conforme literatura específica, o sistema 2 é ativado em situações em que as pessoas estão diante de estímulos que causam surpresa, choque ou perplexidade; que criam necessidade de reflexão sobre algo; ou que demandam que o indivíduo recobre a memória sobre algum evento ${ }^{176}$. Nesse sentido, em prol da dissuasão a comportamentos suicidas, acreditamos que possa ser efetiva a fixação de placas em hotspots com conteúdo capaz de ativar o sistema 2, seja por exemplo uma obra de arte surrealista ou um desafio matemático. Um estudo suíço, analisando a efetividade da instalação de sinais em hotspots, ainda que promovida com base em fundamento diverso, concluiu por sua capacidade de interferir, positivamente, na redução de índices de suicídios ${ }^{177}$.

ponível em: <http://journals.sagepub.com/doi/full/10.1177/0956797617702501>. Acesso em: 13 mar. 2018.

173 LOPES, P.; BARREIRA, D.; PIRES, A. Tentativa de suicídio na adolescência: avaliação do efeito de gênero na depressão e personalidade. Psicologia, Saúde \& Doenças, v. 2, n. 1, p. 47-57, 2001. p. 49; WERNECK, G. et al. Tentativas de suicídio em um hospital geral no Rio de Janeiro, Brasil. Cadernos de Saúde Pública, Rio de Janeiro, v. 22, n. 10, p. 2201-2206, out. 2006. p. 2202; CHACHAMOVICH, E. et al. Quais são os recentes achados clínicos sobre a associação entre depressão e suicídio?. Revista Brasileira de Psiquiatria, v. 31, Supl. 1, p. 518-525. p. 519; SANTOS, S. et al. Prevalência de transtornos mentais nas tentativas de suicídio em um hospital de emergência no Rio de Janeiro, Brasil. Cadernos de Saúde Pública, Rio de Janeiro, v. 25, n. 9, p. 2064-2074, set. 2009. p. $2067-2068$. 174 KREITMAN, N. Parasuicide. Londres: Wiley, 1977.; KURZ, A. et al. The psychiatric management of parasuicide patients. Psychiatrische Praxis, v. 11, p. 6-13, 1984; MÖLLER, H. Efficacy of different strategies of after-care for patients who have attempted suicide. Journal of the Royal Society of Medicine, v. 82, p. 643-647, 1989; BRONISCH, T.; HECHT, H. Prospective long-term follow-up of depressed patients with and without suicide attempts. European Archives of Psychiatry and Clinical Neuroscience, v. 242, n. 1, p. 13-19, sep. 1992. 175 MOTTO, J.; BOSTROM, A.; Randomized controlled trial of postcrisis suicide prevention. Psychiatric Services, v. 52, n. 6, p. 828-833, june 2001.

176 KAHNEMAN, D. Thinking, fast and slow. London: Allen Lane, 2011. p. 19-97.

177 HEMMER, A.; MEIER, P.; REISCH, T. Comparing different suicide prevention measures at bridges and buildings: lessons 
4. Sabe-se que o suicida, ao usar meios com alta letalidade, como a ingestão de medicamentos ou pesticidas ou a queima de carvão, quer melhorar sua condição; não quer piorá-la ou passar por grande sofrimento. Esses meios costumam ter em suas embalagens alertas destacados de perigo de morte. Em razão do exposto, acreditamos que destaque para o perigo de morte deveria ser substituído por alertas voltados aos efeitos indesejados. Por exemplo, em vez de anunciar que um produto pode causar morte, é preferível que sejam anunciados males como dores muito fortes, incapacidade motora ou danos cognitivos permanentes.

\section{REFERÊNCIAS}

ADINKRAH, M. Anti-suicide laws in nine african countries: criminalization, prosecution and penalization. African Journal of Criminology and Justice Studies, v. 9, n. 1, p. 279-292, may 2016.

ADINKRAH, M. Criminal prosecution of suicide attempt survivors in Ghana. International Journal of Offender Therapy and Comparative Criminology, v. 57, n. 12, p. 1477-1497, 2012.

ADORNO, R. Nonphysician-assisted suicide in Switzerland. Cambridge Quarterly of Healthcare Ethics, v. 22, n. 3, p. 246-253, july 2013.

AHMAD, R. et al. Acute poisoning due to commercial pesticides in Multan. Pakistan Journal of Medical Sciences, v. 18, n. 3, p. 227-231, july/sep. 2002.

AHN, M. et al. Gender ratio comparisons of the suicide rates and methods in Korea, Japan, Australia, and the United States. Journal of Affective Disorders, v. 142, n. 1-3, p. 161-165, dec. 2012.

AJDACIC-GROSS, V. et al. Firearm suicides and availability of firearms: the swiss experience. European Psychiatry, v. 25, p. 432-434, 2010.

ANDERSON, E. What is the point of equality? Ethics, v. 109, n. 2, p. 287-337, 1999.

ANESTIS, M.; ANESTIS, J. Suicide rates and state laws regulating access and exposure to handguns. American Journal of Public Health, v. 105, n. 10, p. 2049-2058, oct. 2015.

ARAMESH, K.; SHADI, H. Euthanasia: an islamic ethical perspective. Iranian Journal of Allergy, Asthma and Immunology, v. 6, n. 5, p. 35-38, feb. 2007.

ASSOCIAÇÃO BRASILEIRA DE PSIQUIATRIA. Manual para a imprensa: boas práticas de comunicação e guia com recomendações para um texto claro e esclarecedor sobre doenças mentais e psiquiatria. 2. ed. Rio de Janeiro: ABO, 2009.

AVANCI, R. et al. Perfil do adolescente que tenta suicídio em uma unidade de emergência. Revista Brasileira de Enfermagem, v. 58, n. 5, p. 535-539, set./out. 2005.

BALDWIN, R. From regulation to behaviour change: giving nudge the third degree. Modern Law Review, v. 77, n. 6, p. 831-857, 2014.

BANERJEE, G. et al. The vulnerability of indian women to suicide a field-study. Indian J. Psychiatry, v. 32, n. 4, p. 305-308, oct. 1990.

BARBER, C.; MILLER, M. Reducing a suicidal person's access to lethal means of suicide: a research agenda. American Journal of Preventive Medicine, v. 47, n. 352, p. 264-272, 2014.

BARBUSCIA, D.; RODRIGUES-JÚNIOR, A. Completude da informação nas Declarações de Nascido Vivo e nas Declarações de Óbito, neonatal precoce e fetal, da região de Ribeirão Preto, São Paulo, Brasil, 2000-2007. Cadernos de Saúde Pública, Rio de Janeiro, v. 27, n. 6, p. 1192-1200, jun. 2011.

we have learned from a national survey in Switzerland. Plos One, v. 12, n. 1 jan. 2017. 
BENARTZI, S. et al. Should governments invest more in nudging? Psychological Science, Thousand Oaks, june 2017. Disponível em: <http://journals.sagepub.com/doi/full/10.1177/0956797617702501>. Acesso em: 13 mar. 2018.

BENNEWITH, O.; NOWERS, M.; GUNNEL D. Effect of barriers on the Clifton suspension bridge. The British Journal of Psychiatry, v. 190, p. 266-267, mar. 2007.

BERLIN, I. Two concepts of liberty. In: BERLIN, I. Four essays on liberty. Oxford: Oxford University Press, 1969.

BETZ, M. et al. Lethal means access and assessment among suicidal emergency department patients. Depression and Anxiety, v. 33, n. 6, p. 502-511, june 2016.

BOVENS, L. The ethics of nudge. In: GRÜNE-YANOFF, T.; HANSON, S. Preference change: approaches from philosophy, economics and psychology. Berlin: Springer, 2009. Cap. 10.

BRÅDVIK, L.; BERGLUND, M. A suicide peak after weekends and holidays in patients with alcohol dependence. Suicide and Life-Threatening, v. 33, n. 2, p. 186-191, summer 2003.

BRASIL. Ministério do Planeamento, Orçamento e Gestão. Instituto Brasileiro de Geografia e Estatística. Censo demográfico 2010: características gerais da população, religião e pessoas com deficiência. Rio de Janeiro: IBGE, 2012.

BRASIL. Ministério do Planeamento, Orçamento e Gestão. Instituto Brasileiro de Geografia e Estatística. Censo demográfico 2010: características gerais da população e dos domicílios: resultado do universo. Rio de Janeiro: IBGE, 2011.

BRASIL. Ministério do Planeamento, Orçamento e Gestão. Instituto Brasileiro de Geografia e Estatística. Censo demográfico 2000: características gerais da população e dos domićlios: resultado da amostra. Rio de Janeiro: IBGE, 2003.

BRASIL. Ministério do Planeamento, Orçamento e Gestão. Instituto Brasileiro de Geografia e Estatística. Nota metodológica: projeção da população do Brasil por sexo e idade para o período 2000/2060; projeção da população das Unidades da Federação por sexo e idade para o período 2000/2030. Rio de Janeiro: IBGE, 2015.

BRASIL. Ministério do Planeamento, Orçamento e Gestão. Instituto Brasileiro de Geografia e Estatística. Projeção da população: Brasil e Unidades da Federação. Rio de Janeiro: IBGE, 2013.

BRASIL. Ministério do Planeamento, Orçamento e Gestão. Instituto Brasileiro de Geografia e Estatística. Diretoria de Pesquisas. Coordenação de População e Indicadores Sociais. Nota técnica: estimativas da população dos municípios brasileiros com data de referência em 1º de julho de 2014. Rio de Janeiro: IBGE: 2015.

BREUER, H.; BREUER, J.; FISCHBACH-BREUER, B. Social, toxicological and meteorological data on suicide attempts. European archives of Psychiatry and Clinical Neuroscience, v. 235, p. 367-370, 1986.

BRONISCH, T.; HECHT, H. Prospective long-term follow-up of depressed patients with and without suicide attempts. European Archives of Psychiatry and Clinical Neuroscience, v. 242, n. 1, p. 13-19, sep. 1992.

BRUCE-BRIGGS, B. The great american gun war. The Public Interest, n. 45, p. 37-62, 1976.

BULLUSU, L.; ALDERSON, M. Suicides 1950-82. Population Trends, v. 35, p 11-17, spring 1984.

CALO, R. Code, nudge, or notice? Iowa Law Review, v. 99, n. 2, p. 773-802. 2014.

CAMPOS, F. Síntese da reorganização Nacional (entrevista concedida à imprensa, em abril de 1939). In: CAMPOS, F. O Estado Nacional: sua estrutura, seu conteúdo ideológico. Brasília: Senado Federal, 2001. p. 107-136. 
ÇETIN, G.; GÜNAY, Y.; FINCANCI, S. et al. Suicides by jumping from Bosphorus Bridge in Istanbul. Forensic Science International, v. 116, n. 2-3, p. 157-162, feb. 2001.

CHACHAMOVICH, E. et al. Quais são os recentes achados clínicos sobre a associação entre depressão e suicídio?. Revista Brasileira de Psiquiatria, v. 31, Supl. 1, p. 518-525.

CHEN, Y.; PARK, N.; LU, T. Suicide methods used by women in Korea, Sweden, Taiwan and the United States. Journal of the Formosan Medical Association, v. 108, n. 6, p. 452-459, june 2009.

CHEN, Y.; YIP, P. Prevention of suicide by jumping: experiences from Taipei City (Taiwan), Hong Kong and Singapore. In: WASSERMAN, D.; WASSERMAN, C. Oxford textbook of suicidology and suicide prevention. Oxford: Oxford University Press, 2009. p. 569-572.

CHUNG, Y. et al. The effectiveness of platform screen doors for the prevention of subway suicides in South Korea. Journal of Affective Disorders, v. 194, p. 80-83, apr. 2016.

CLARKE, S. A definition of paternalism. Critical Review of International Social and Political Philosophy, v. 5, n. 1, p. 81-91, 2002.

CONLY, S. Against autonomy: justifying coercive paternalism. Cambridge: Cambridge University Press, 2013.

CONNER, K.; ZHONG, Y. State firearm laws and rates of suicide in men and women. American Journal of Preventive Medicine, v. 25, n. 4, p. 320-324, 2003.

DAHLBERG, L.; IKEDA, R.; KRESNOW, M. Guns in the home and risk of a violent death in the home: findings from a national study. American Journal of Epidemiology, v. 160, n. 10, p. 929-936, nov. 2004.

DAMAS, F. et al. Tentativas de suicídio com agentes tóxicos: análise estatística dos dados do CIT/SC (1994 a 2006). Revista Brasileira de Toxicologia, v. 22, n. 1-2, p. 21-26, 2009.

DIAS, D.; NONATO, D.; RAIOL, R. Interação entre a acessibilidade urbanística e o direito à cidade: possibilidade de inclusão social das pessoas com deficiência. Revista Brasileira de Políticas Públicas, v. 7, n. 2, p. 149-168, ago. 2017.

DOGANAY, Z. et al. Climatic and diurnal variation in suicide attempts in the ED. American Journal of Emergency Medicine, v. 21, n. 4, p. 271-275, july 2003.

DWORKIN, G. Defining paternalism. In: COONS, C.; WEBER, M. Paternalism: theory and practice. Cambridge: Cambridge University Press, 2013.

DWORKIN, G. Moral paternalism. Law and Philosophy, v. 24, n. 3, p. 305-319, 2005.

DWORKIN, G. Paternalism: some second thoughts. In: SARTORIUS, R. Paternalism. Minneapolis: University of Minnesota Press, 1983.

ELNOUR, A.; HARRISON, J. Lethality of suicide methods. Injury Prevention, v. 14, p. 39-45, 2008.

FAÇANHA, M. et al. Busca ativa de óbitos em cemitérios da Região Metropolitana de Fortaleza, 1999 a 2000. Epidemiologia e Serviços de Saúde, v. 12, n. 3, p. 131-136.

FEINBERG, J. Harm to self: the moral limits to the criminal law. Oxford: Oxford University Press, 1986. v. 3.

FERGUSON, P. Moving from preparation to perpetration? Attempted crimes and breach of the peace in scots law. Ohio State Journal of Criminal Law, v. 11, n. 2, p. 687-700, 2014.

FERREIRA, F.; POTTUMATI, E. A licitação pública como instrumento de desenvolvimento na perspectiva do paternalismo. Revista Brasileira de Políticas Públicas, v. 4, n. 1, p. 201-213, jan./jun. 2014.

FERREIRA, M.; FIGUEIREDO, M. Epidemiologia das intoxicações humanas por raticidas no Brasil. Revista Eletrônica Gestão \& Saúde, v. 4, n. 3, p. 861-870, 2013. 
FREDERICK, S.; LOEWENSTEIN, G.; O'DONOGHUE, T. Time discounting and time preference: a critical review. Journal of Economic Literature, v. 150, n. 2, p. 351-401, 2002.

FREITAS, E. O suicídio em Portugal no Século XX: elementos empíricos para uma pesquisa. Finisterra, Lisboa, v. 18, n. 34, p. 267-300, 1982.

GERT, B.; CULVER, C. The justification of paternalism. Ethics, v. 89, n. 2, p. 199-210, jan. 1979.

GLAT'T, K. Helpline: suicide prevention at a suicide site. Suicide Life-Threatening Behavior, v. 17, n. 4, p. 299309, winter 1987.

GRÜNE-YANOFF, T.; HERTWIG, R. Nudge versus boost: how coherent are policy and theory? Minds and Machines, v. 26, n. 1, p. 149-183, 2016.

GUNNEL, D. et al. The epidemiology and prevention of suicide by hanging: a systematic review. International Journal of Epidemiology, v. 34, p. 433-442, 2005.

GUNNEL, D. et al. The impact of pesticide regulations on suicide in Sri Lanka. International Journal of Epidemiology, v. 36, p. 1235-1242, 2007.

GUNNEL, D.; NOWERS, M. Suicide by jumping. Acta Psychiatrica Scandinavica, v. 96, p. 1-6, 1997.

HABENSTEIN, A. et al. Chances and limits of method restriction: a detailed analysis of suicide methods in Switzerland. Archives of Suicide Research, v. 17, n. 1, p. 75-87, 2013.

HANNIKAINEN, I. et al. A deterministic worldview promotes approval of state paternalism. Journal of Experimental Social Psychology, v. 70, p. 251-259, may 2017.

HANSEN, P. The definition of nudge and libertarian paternalism: does the hand fit the glove? The European Journal of Risk Regulation, v. 7, n. 1, p. 155-174, mar. 2016.

HASSAN, R. Temporal variation in suicide occurrence in Australia: a research note. The Australian \& New Zealand Journal of Statistics, v. 30, n. 2, p. 194-202, aug. 1994.

HECKMANN, I. C. et al. Análise do preenchimento de declarações de óbitos em localidade do Estado do Rio Grande do Sul (Brasil). Revista de Saúde Pública, S. Paulo, v. 23, n. 4, p. 292-297, 1989.

HEMMER, A.; MEIER, P.; REISCH, T. Comparing different suicide prevention measures at bridges and buildings: lessons we have learned from a national survey in Switzerland. Plos One, v. 12, n. 1, jan. 2017.

HERNETKOSKI, M.; KESKINEN, E.; PAKKARI, I. Driver suicides in Finland: are they different in northern and Southern Finland? International Journal of Circumpolar Health, v. 68, n. 3, p. 249-260, 2009.

HESKETH, J.; CASTRO, A. Fatores correlacionados com a tentativa de suicídio. Revista de Saúde Pública, v. 12, p. 138-146, 1978.

HOEK, W. et al. Pesticide poisoning: a major health problem in Sri Lanka. Social Science \& Medicine, v. 46, n. 4-5, p. 495-504, feb. 1998.

HURST, S.; MAURON, A. Assisted suicide in Switzerland: clarifying liberties and claims. Bioetbics, v. 31, n. 3, p. 199-208, mar. 2017.

JESSEN, G.; JENSEN, B. Postponed suicide death? Suicides around birthdays and major public holidays. Suicide and Life-Threatening Behavior, v. 29, n. 3, p. 272-283, fall 1999.

JOHN, P.; SMITH, G.; STOKER, G. Nudge nudge, think think: two strategies for changing civic behaviour. Political Quarterly, v. 80, n. 3, p. 361-370, july 2009.

JOLLS, C.; SUNSTEIN, C.; THALER, R. A behavioral approach to law and economics. Stanford Law Review, v. 50, p. 1471-1550, 1998. 
JOO, S. et al. Factors associated with suicide completion: a comparison between suicide attempters and completers. Asia-Pacific Psychiatry, v. 8, n. 1, p. 80-86, mar. 2016.

KAHNEMAN, D. Thinking, fast and slow. London: Allen Lane, 2011.

KAHNEMAN, D.; SLOVIC, P.; TVERSKY, A. Judgement under uncertainty: heuristics and biases. Cambridge: Cambridge University Press, 1982.

KALEDIENE, R.; PETRAUSKIENE, J. Inequalities in daily variations of deaths from suicide in Lithuania: identification of possible risk factors. Suicide and Life-Threatening Behavior, v. 34, n. 2, p. 138-146, summer 2004.

KELEDIENE, R.; STARKUVIENE, S.; PETRAUSKIENE, J. Seasonal patterns of suicide over the period of socio-economic transition in Lithuania. BMC Public Health, v. 6, 40, feb. 2006. Disponível em: < http:// www.ncbi.nlm.nih.gov/pmc/articles/PMC1397811>. Acesso em: 14 mar. 2018.

KELLERMAN, A. et al. Suicide in the home in relation to gun ownership. The New England Journal of Medicine, v. 327, n. 7, p. 467-472, aug. 1992.

KHAN, M. et al. Epidemiology of suicide in Pakistan: determining rates in six cities. Archives of Suicide Research, v. 12, n. 2, p. 155-160, 2008.

KHAN, M. et al. Suicides in the developing world: case study from Pakistan. Suicide and Life-Threatening Behavior, v. 36, n. 1, feb. 2006.

KIM, C. et al. Seasonal differences in psychopathology of male suicide completers. Comprehensive Psychiatry, v. 45, n. 5, p. 333-339, sep./oct. 2004.

KLECK, G.; GERTZ, M. Armed resistance to crime: the prevalence and nature of self-defense with a gun. Journal of Criminal Law and Criminology, v. 86, n. 1, p. 150-187, fall 1995.

KLEINIG, J. Paternalism. Manchester: Manchester University Press, 1983.

KOVATS, R.; EBI, K. Heatwaves and public health in Europe. European Journal of Public Health, v. 16, n. 6, p. 592-599, 2006.

KREITMAN, N. Parasuicide. Londres: Wiley, 1977.

KURZ, A.; MÖLLER, H.; BUERK, F. et al. The psychiatric management of parasuicide patients. Psychiatrische Praxis, v. 11, p. 6-13, 1984.

LAURENTI, R.; JORGE, M. H. P. M.; GOTLIEB, S. Informação em mortalidade: o uso das regras internacionais para a seleção da causa básica. Revista Brasileira de Epidemiologia, v. 12, n. 2, p. 195-203, 2009.

LAW, C. et al. Evaluating the effectiveness of barrier installation for preventing railway suicides in Hong Kong. Journal of Affective Disorders, v. 114, n. 1-3, p. 254-262, apr. 2009.

LE GRAND, J.; NEW, B. Government paternalism: nanny State or helpful friend? Princeton: Princeton University Press, 2015.

LEENAARS, A.; LESTER, D. Comparison of rates and patterns of suicide in Canada and the United States, 1960-1988. Death Studies, v. 16, n. 5, p. 417-430, 1992.

LESTER, D. Decriminalization of suicide in New Zealand and suicide rates. Psychological Reports, v. 72, n. 3, p. 1050, june 1993.

LESTER, D. Suicide in emigrants from the Indian subcontinent. Transcultural psycbiatry, v. 37, n. 2, p. 243$254,2000$.

LIN, J.; LU, T. Suicide mortality trends by sex, age and method in Taiwan, 1971-2005. BMC Public He- 
alth [online], v. 8, n. 6, jan. 2008. Disponível em: <https://bmcpublichealth.biomedcentral.com/articles/10.1186/1471-2458-8-6>. Acesso em: 13 mar. 2018.

LOFTIN, C. et al. Effects of restrictive licensing of handguns on homicide and suicide in the District of Columbia. The New England Journal of Medicine, v. 325, n. 23, p. 1615-1620, dec. 1991.

LOPES, P.; BARREIRA, D.; PIRES, A. Tentativa de suicídio na adolescência: avaliação do efeito de gênero na depressão e personalidade. Psicologia, Saúde \& Doenças, v. 2, n. 1, p. 47-57, 2001.

LOVISI, G. et al. Prevalência de transtornos mentais nas tentativas de suicídio em um hospital de emergência no Rio de Janeiro. Cadernos de Saúde Pública, Rio de Janeiro, v. 25, n. 9, p. 2064-2074, set. 2009.

LY, K. et al. A practitioner's guide to nudging. Research Report Series Behavioural Economics in Action, Rotman School of Management, University of Toronto, Toronto, p. 1-28, mar. 2013.

MAES, M. et al. Seasonal variation in Plasma L-Tryptophan availability in healthy volunteers' relationship to violent suicide occurrence. Archives of General Psychiatry, v. 52, p. 937-946, nov. 1995.

MAES, M. et al. Synchronized annual rhythms in violent suicide rate, ambient temperature and the lightdark span. Acta Psychiatrica Scandinavica, v. 90, p. 391-396, 1994.

MARTINS, B. et al. Intoxicação por raticida em um Centro de Assistência Toxicológica. Revista da Rede de Enfermagem do Nordeste, v. 17, n. 1, p. 3-9, jan./fev. 2016.

MARUŠIČ, A. Suicide in Slovenia: lessons for cross-cultural psychiatry. International Review of Psychiatry, v. 11, p. 212-218, 1999.

MASSING, W.; ANGERMEYER, M. The monthly and weekly distribution of suicide. Social Science \& Medicine, v. 21, n. 4, p. 433-441, 1985.

MATSUBAYASHI, T.; SAWADA, Y.; UEDA, M. Does the installation of the blue lights on train platforms prevent suicide? A before-and-after observational study from Japan. Journal of Affective Disorders, v. 147, p. 385-388, 2013.

JORGE, M. H. P. M. Situação atual das estatísticas oficiais relativas à mortalidade por causas externas. Revista de Saúde Pública, São Paulo, v. 24, n. 3, p. 217-223, 1990.

MENDELSON, D.; FRECKELTON, I. The interface of the civil and criminal law of suicide at common law (1194-1845). International Journal of Law and Psychiatry, v. 36, n. 5-6, p. 343-349, 2013.

MILL, J. S. Essays on some unsettled questions of political economy. Kitchner: Batoche Books, 2000.

MILL, J. S. On liberty. London: Floating Express, 2009.

MILLER, M. et al. The association between changes in household firearm ownership and rates of suicide in the United States, 1981-2002. Injury Prevention, v. 12, n. 3, p. 178-182, june 2006.

MINAYO, M. C.; CAVALCANTE, F. G. Suicídio entre pessoas idosas: revisão da literatura. Revista de Saúde Pública, v. 44, n. 4, p. 750-757, 2010.

MISHARA, B.; WESSTUB, D. The legal status of suicide: a global review. International Journal of Law and Psycbiatry, v. 44, p. 54-74, jan./ feb., 2016.

MITCHELL, G. Libertarian paternalism is an Oxymoron. Northwestern University Law Review, v. 9, n. 3, p. 1245-1277, 2005.

MÖLLER, H. Efficacy of different strategies of after-care for patients who have attempted suicide. Journal of the Royal Society of Medicine, v. 82, p. 643-647, 1989.

MOTTO, J.; BOSTROM, A. Randomized controlled trial of postcrisis suicide prevention. Psycbiatric Services, 
v. 52, n. 6, p. 828-833, june 2001.

NAKAMURA, J. et al. Temporal variation in adolescent suicide attempts. Suicide and Life-Threatening Behavior, v. 24, n. 4, p. 343-349, 1994.

NEELEMAN, J. Suicide as a crime in the UK: legal history, international comparisons and present implications. Acta Psychiatrica Scandinavica, v. 94, n. 4, p. 252-257.

NISHI, M. et al. Relationship between suicide and holidays. Journal of Epidemiology, v. 10, n. 5, p. 317-320, sep. 2000.

ORGANIZAÇÃO MUNDIAL DE SAÚDE. World Health Statistics 2014. Itália: WHO Graphics, 2014.

ORGANIZAÇÃO MUNDIAL DE SAÚDE. World Health Statistics 2015. Luxemburgo: WHO Graphics, 2015.

OSAFO, J. et al. "We now have a patient and not a criminal": an exploratory study of judges and lawyers' views on suicide attempters and the law in Ghana. International Journal of Offender Therapy and Comparative Criminology [online], p. 1-21, jan. 2017. Disponível em: <http://journals.sagepub.com/doi/ abs/10.1177/0306624X17692059>. Acesso em: 13 mar. 2018.

OSMAN, M.; PARNELL, A.; HALEY, C. "Suicide shall cease to be a crime": suicide and undetermined death trends 1970-2000 before and after the decriminalization of suicide in Ireland 1993. Irish Journal of Medical Science, v. 186, n. 1, p. 201-205, feb. 2017.

OWENS, C. et al. Suicide in public places: findings from one English county. European Journal of Public Health, v. 19, n. 6, p. 580-582, apr. 2009.

PAGE, L.; HAJAT, S.; KOVATS, S. Relationship between daily suicide counts and temperature in England and Wales. British Journal of Psychiatry, v. 191, p. 106-112, aug. 2007.

PATEL, V. et al. Suicide mortality in India: a nationally representative survey. The Lancet, v. 379, p. 23432351, 2012.

PHILLIPS, D.; SANZONE, A. A comparison of injury date and death date in 42,698 suicides. American Journal of Public Health, v. 78, n. 5, p. 541-543, may 1988.

PHILLIPS, M.; LIU, H.; ZHANG, Y. Suicide and social change in China. Culture, Medicine and Psychiatry, v. 23, p. 25-50, 1999.

PIRES, M. C. Indicadores de risco para tentativa de suicídio por envenenamento: um estudo de caso-controle. 2014. 145 f. Tese (Doutorado) - Programa de Pós-Graduação em Neuropsiquiatria e Ciências do Comportamento, Universidade Federal de Pernambuco, Recife, 2014.

PIRKIS, J.; SPITTAL, M. The effectiveness of structural interventions at suicide hotspots: a meta-analysis. International Journal of Epidemiology, v. 42, p. 531-548, 2013.

POPE, T. M. Counting the Dragon's Teeth and Claws: the definition of hard paternalism. Georgia State University Law Review, v. 20, n. 3, p. 659-722, 2004.

PRITCHARD, C.; HEAN, S. Suicide undetermined deaths among youths and young adults in Latin America: comparison with the 10 major developed countries: a source of hidden suicides? Crisis, v. 29, n. 2, p. 145-153, 2008.

RADHAKRISHNAN, R.; ANDRADE, C. Suicide: an indian perspective. Indian Journal of Psychiatry, [online], v. 54,p.304-319,2012.Disponível em:<http://www.indianjpsychiatry.org/text.asp?2012/54/4/304/104793>. Acesso em: 13 mar. 2018.

RAJENDRA, R. et al. A feasibility study to establish a deliberate self-harm register in a state hospital in Sou- 
thern India. British Journal of Medical Practioners [online], v. 8, n. 1, mar. 2015. Disponível em: <http://www. bjmp.org/content/ feasibility-study-establish-deliberate-self-harm-register-state-hospital-southern-india $>$. Acesso em: 10 mar. 2018.

RATNAYEKE, L. Suicide and crisis intervention in rural communities in Sri Lanka: a column from befrienders international. Crisis, v. 17, n. 4, p. 149-151, 1996.

REBONATO, R. Taking liberties: a critical examination of libertarian paternalism. Houndmills: Palgrave Macmillan, 2012.

REISCH, T. et al. Change in suicides rates in Switzerland before and after firearm restriction resulting from the 2003 "Army XXI" reform. The American Journal of Psychiatry, v. 170, n. 9, p. 977-984, sep. 2013.

REISCH, T.; MICHEL, K. Securing a suicide hot spot: effects of a safety net at the Bern Muenster Terrace. Suicide and Life-Threatening Behavior, v. 35, n. 4, p. 460-467, aug. 2005.

ROBERTS, D. et al. Influence of pesticide regulation on acute poisoning deaths in Sri Lanka. Bulletin of the World Health Organization, v. 81, n. 11, p. 789-798, 2003.

ROSENGART, M. et al. An evaluation of state firearm regulations and homicide and suicide death rates. Injury Prevention, v. 11, n. 2, p. 77-83, apr. 2005.

RUNESON, B. et al. Method of attempted suicide as predictor of subsequent successful suicide: national long term cohort study. BMJ [online], v. 341, 2010. Disponível em: <https://www.ncbi.nlm.nih.gov/pmc/ articles/PMC2903664>. Acesso em: 14 mar. 2018.

SÁ, N. B. et al. Atendimentos de emergência por tentativas de suicídio. Revista Médica de Minas, v. 20, n. 2, p. 145-152, 2010.

SAMSON, A. The behavioral economics guide 2016. (with introduction by Gerd Gigerenzer). Londres: Behavioral Science Solutions, 2016.

SANTOS, S. et al. Prevalência de transtornos mentais nas tentativas de suicídio em um hospital de emergência no Rio de Janeiro, Brasil. Cadernos de Saúde Pública, Rio de Janeiro, v. 25, n. 9, p. 2064-2074, set. 2009.

SAREEN, H.; TRIVEDI, J. Legal implications of suicide problems specific to South Asia. Delbi Psychiatry Journal, v. 12, n. 1, p. 121-125, apr. 2009.

SCHNITMAN, A. Análise da fidedignidade da declaração da causa básica de morte por câncer em Salvador, Brasil. Revista de Saúde Pública, São Paulo, v. 24, n. 6, p. 490-496, 1990.

SHENASSA, E.; CATLIN, S.; BUKA, S. Lethality of firearms relative to other suicide methods: a population based study. Journal of Epidemiology and Community Health, v. 57, n. 2, p. 120-124, feb. 2003.

SHIFFRIN, S. V. Paternalism, unconscionability doctrine, and accommodation. Philosophy and Public Affairs, v. 29, n. 3, p. 205-250, 2000.

SILVA, J. A. et al. Declaração de óbito, compromisso no preenchimento: avaliação em Belém - Pará, em 2010. Revista da Associação Médica Brasileira, v. 59, n. 4, p. 335-340, 2013.

SIMÕES, E.; REICHNHEIM, M. Confiabilidade das informações da causa básica nas declarações de óbito por causas externas em menores de 18 anos no Município de Duque de Caxias - RJ. Cadernos de Saúde Pública, Rio de Janeiro, v. 17, n. 3, p. 521-531, 2001.

SIMON, H. A behavioral model of rational choice. Quarterly Journal of Economics, v. 69, n. 1, p. 99-118, feb. 1955.

SINYOR, M.; LEVITT, A. Effect of a barrier at Bloor Street Viaduct on suicide rates in Toronto: natural experiment. BMJ, v. 341, july 2010. 
SINYOR, M. et al. Did the suicide barrier work after all? Revisiting the Bloor Viaduct natural experiment and its impact on suicide rates in Toronto. BMJ Open, v. 7, n. 5, june 2017.

SOUZA, E.; MINAYO, M. C.; CAVALCANTE, F. G. O impacto do suicídio sobre a morbimortalidade da população de Itabira. Ciência \& Saúde Coletiva, v. 11, n. Sup., p. 1333-1342, 2007.

STECK, N. et al. Euthanasia and assisted suicide in selected European countries and US States. Systematic literature review. Med Care, v. 51, n. 10, p. 938-944, oct. 2013.

STEIDLEY, T.; COLEN, C. Framing the gun control debate: press releases and framing strategies on the National Rifle Association and the Brady Campaign. Social Science Quarterly, v. 98, n. 2, p. 608-627, june 2017.

SUNSTEIN, C. Choosing not to choose: understanding the value of choice. New York: Oxford University Press, 2015.

SUNSTEIN, C. Nudging: a very short guide. Journal of Consumer Policy, v. 37, n. 4, p. 583-588, dec. 2014.

SUNSTEIN, C. Why nudge?: the politics of libertarian paternalism. New Haven: Yale University Press, 2014.

THALER, R.; SUNSTEIN, C. Libertarian paternalism. American Economic Review, v. 93, n. 2, p. 175-179, may 2003.

THALER, R.; SUNSTEIN, C. Nudge: Improving Decisions about Health, Wealth and Happiness. New Haven: Yale University Press, 2008.

TURRINI, R.; SANTO, A. Infecção hospitalar e causas múltiplas de morte. Jornal de Pediatria, v. 78, n. 6, p. 485-490, 2002.

TVERSKY, A.; KAHNEMAN, D. Advances in prospect theory: cumulative representation of uncertainty. Journal of Risk and Uncertainty, v 5, p. 297-323, 1992.

TVERSKY, A.; KAHNEMAN, D. Judgment under uncertainty: heuristics and biases. Science, v. 185, n. 4157, p. 1124-1131, sep. 1974.

UEDA, M.; SAWADA, Y.; MATSUBAYASHI, T. The effectiveness of installing physical barriers for preventing railway suicides and accidents: evidence from Japan. Journal of Affective Disorders, v. 178, p. 1-4, 2015.

UNITED STATES OF AMERICA. Department of Health and Human Services. Centers for Disease Control and Prevention. National Center for Health Statistics. National Vital Statistics Reports. Deaths: Leading Causes for 2013, v. 64, n. 2, feb. 2016.

VANDERLEI, L. et al. Avaliação da confiabilidade da causa básica de óbito em unidade terciária de atenção à Saúde materno-infantil. Informe Epidemiológico do SUS, v. 11, n. 1, p. 15-23, 2002.

VANDEVEER, D. Paternalistic intervention: the moral bounds of benevolence. Princeton: Princeton University Press, 1986.

VÄRNIK, A. et al. Suicide methods in Europe: a gender-specific analysis of countries participating in the "European Alliance Against Depression". Journal of Epidemiology and Community Health, v. 62, p. 545-551, 2008.

VÄRNIK, P. Suicide in the world. International Journal of Environmental Research and Public Health, v. 9, p. 760$771,2012$.

WERNECK, G. et al. Tentativas de suicídio em um hospital geral no Rio de Janeiro, Brasil. Cadernos de Saúde Pública, Rio de Janeiro, v. 22, n. 10, p. 2201-2206, out. 2006.

WHITMER, D.; WOODS, D. Analysis of the cost effectiveness of a suicide barrier on the Golden Gate Bridge. Crisis, v. 24, n. 2, p. 98-106, 2013. 
WINTEMUTE, G. et al. Mortality among recent purchasers of handguns. The New England Journal of Medicine, v. 341, n. 21, p. 1583-1589, 1999.

WITHERS, R. Status of suicide as a crime. The Virginia Law Register, v. 19, n. 9, p. 641-647, jan. 1914.

WU, K; CHEN, Y.; YIP, P. Suicide methods in Asia: implications in suicide prevention. International Journal of Environmental Research and Public Health, v. 9, p. 1135-1158, 2012.

YANG, L.; CHO, S.; SEO, H. Effects of light color on consumers: acceptability and willingness to eat apples and bell peppers. Journal of Sensory Studies, v. 31, n. 1, p. 3-11, nov. 2016.

YIP, P. et al. Means restriction for suicide prevention. Lancet, v. 23, n. 379, p. 2393-2399, june 2012.

YIP, P. et al. Restricting the means of suicide by charcoal burning. The British Journal of Psychiatry, v. 196, p. 241-242, 2010.

YIP, P.; LIU, K. The ecological fallacy and the gender ratio of suicide in China. British Journal of Psychiatry, v. 189, p. 465-466, 2006.

YOSHIOKA, E. et al. Time trends in method-specific suicide rates in Japan, 1990-2011. Epidemiology and Psychiatric Sciences, v. 25, n. 1, p. 58-68, feb. 2016.

ZIEGLER, S.; BOSSHARD, G. Role of non-governmental organisations in physician assisted suicide. BMJ, v. 334, p. 295-298, feb. 2007.

ZONDA, T. et al. The impact of holidays on suicide in Hungary. Omega, v. 58, n. 2, p. 153-162, 2008/2009. 
Para publicar na revista Brasileira de Políticas Públicas, acesse o endereço eletrônico www.rbpp.uniceub.br

Observe as normas de publicação, para facilitar e agilizar o trabalho de edição. 